\title{
Numerical modeling of shoreline undulations part 2: Varying wave climate and comparison with observations
}

\author{
Kærgaard, Kasper Hauberg; Fredsøe, Jørgen
}

Published in:

Coastal Engineering

Link to article, DOI:

10.1016/j.coastaleng.2012.11.003

Publication date:

2013

Document Version

Publisher's PDF, also known as Version of record

Link back to DTU Orbit

Citation (APA):

Kærgaard, K. H., \& Fredsøe, J. (2013). Numerical modeling of shoreline undulations part 2: Varying wave climate and comparison with observations. Coastal Engineering, 75, 77-90.

https://doi.org/10.1016/j.coastaleng.2012.11.003

\section{General rights}

Copyright and moral rights for the publications made accessible in the public portal are retained by the authors and/or other copyright owners and it is a condition of accessing publications that users recognise and abide by the legal requirements associated with these rights.

- Users may download and print one copy of any publication from the public portal for the purpose of private study or research.

- You may not further distribute the material or use it for any profit-making activity or commercial gain

- You may freely distribute the URL identifying the publication in the public portal

If you believe that this document breaches copyright please contact us providing details, and we will remove access to the work immediately and investigate your claim. 


\title{
Numerical modeling of shoreline undulations part 2: Varying wave climate and comparison with observations
}

\author{
Kasper Kaergaard*, Jørgen Fredsoe \\ Coastal, Maritime and Structural Engineering, Department of Mechanical Engineering, Danish Technical University, Niels Koppels Allé 403, 2800 Kgs. Lyngby, Denmark
}

\section{A R T I C L E I N F O}

\section{Article history:}

Received 22 February 2012

Received in revised form 4 November 2012

Accepted 7 November 2012

Available online 20 December 2012

\section{Keywords:}

Shoreline undulations

Shoreline spit

Numerical model

West coast of Namibia

West coast of Denmark

\begin{abstract}
A B S T R A C T
The present work applies the shoreline model from part 1 to a real environment. In part 1, a numerical shoreline model which could handle the development of arbitrarily shaped shorelines was applied to consider the development of shoreline undulations on an unstable shoreline exposed to incoming waves with a directional spreading. In this paper, these findings are extended to firstly include the effect of a varying wave climate on the shoreline morphology and secondly, to tune the model to two naturally occurring shorelines. It is found that the effect of a variable wave climate is to slow down the development of the morphology and in some cases to inhibit the formation of shore-parallel spits at the crest of the undulations. On one of the natural shorelines, the west coast of Namibia, the shore is exposed to very obliquely waves from one main direction. Here, the shoreline model is able to describe the observed shoreline features qualitatively and quantitatively. The model slightly over-predicts the scale of the feature and, associated with this, slightly under-predicts the migration speeds of the features. On the second shoreline, the west coast of Denmark, the shore is exposed to waves with an angle close to the critical around $45^{\circ}$, and here the existence of undulations is discussed in detail.
\end{abstract}

(c) 2012 Published by Elsevier B.V.

\section{Introduction}

Modeling of coastal morphodynamic processes needs to be verified with the coastal behavior in real life to check the accuracy of the model and its applicability as an engineering tool. Regarding small scale morphology like bed forms you can verify the model by comparing with laboratory experiments, while with increasing size of the features you investigate, you need to go to the field. Features like breaker bars can partly be investigated in large scale laboratory facilities, but you need to keep an eye with the similar behavior of these bars in nature to get a realistic description and understanding of these features (crescendic bars, interaction with rip currents, scale effects, etc). In part 1 of this study, (Kaergaard and Fredsoe (2013b) abbreviated to KF) we have developed a tool - a numerical model - to describe the shoreline behavior of a coast exposed to very obliquely incoming waves as done earlier by Ashton and Murray (2006b) and Falqués and Calvete (2005). The KF model is very detailed and accounts for wave refraction along a curved shoreline and inertia in long shore current. On the other hand it is simplified like the other above mentioned models by applying a one-line modeling approach, in which the cross-sectional shape of the coastal profile perpendicular to the local shoreline orientation is prescribed and kept constant during the shoreline evolution. The scale of

\footnotetext{
* Corresponding author. Tel.: + 4531342670 .

E-mail addresses: kak@dhigroup.dk (K. Kaergaard), jofr@mek.dtu.dk (J. Fredsoe).
}

shoreline features like undulations formed by obliquely incoming waves is large, usually many times the width of the surf zone (Falqués and Calvete (2005) and Uguccioni et al. (2006)) and cannot be studied experimentally in the lab without huge scale effects. For this reason, you need to compare the model ability with observations from the field, where the forcing from waves and current on the sediment transport is much more complex than what you usually have in the laboratory.

\subsection{Scope of the present work}

In this paper, we compare the model predictions with two field cases, where we have sufficient information regarding waves and current to make a reasonable comparison. The two cases are also selected so they highlight two different scenarios: in one case (Namibia), the shore is exposed to very obliquely incoming waves from one main direction, so undulations along the shore are large and clearly recognizable. Here we study the resulting shape, where you get a nearly shore parallel spit formed at the crest of the undulation, which until now has not been satisfactory described, especially regarding the angle of the spit with the shore.

At the other location (Denmark), the average angle of the incoming waves is not far away from the critical one between an unstable and a stable angle regarding formations of large scale undulations along the shore (about $45^{\circ}$ ), furthermore the direction of the incoming waves cover a large range. This provides an opportunity to investigate whether undulations will be formed in an environment where the angle sometimes is larger and sometimes smaller than the critical. 
The structure of the paper is: firstly the theoretical results regarding shoreline undulations in KF, are extended to the case of a varying wave climate. Next, the numerical shoreline model is used to the natural shorelines described above and a quantitative comparison between the model predictions and field observations is made.

\section{Simulations for varying wave climates}

\subsection{Hydrodynamic parameters}

The hydrodynamic parameters applied by KF are wave height, wave period, wave direction and directional spreading to control the forcing. The constant wave conditions should represent those time averaged conditions, which should give the same morphological evolution as if the full time varying conditions were used.

In coastal engineering and coastal geomorphology, the wave climate is rarely specified as only an average wave height, average wave period and average wave direction. This is because information crucial to the understanding of the geomorphological processes is lost when using simple averaging. In nature, these parameters are variable on several different time scales: the individual waves vary within one wave group, the significant wave height varies during one storm and the intensities of different storms also vary.

To understand the evolution of the large scale shoreline features in the present work, the degree of detail needed in the wave forcing is limited, therefore in the present work wave climates are included by following the approach by Ashton and Murray (2006b), where two parameters $A$ and $U$ were specified. $U$ is the fraction of waves coming from the unstable wave regime meaning directions larger than $45^{\circ}$ and smaller than $-45^{\circ}$, i.e. from direction intervals $\Delta \alpha_{1}$ and $\Delta \alpha_{4}$ shown in Fig. 1. $A$ is the fraction of waves coming from the left, meaning the fraction of waves from directions smaller than $0^{\circ}$, i.e. from direction intervals $\Delta \alpha_{1}$ and $\Delta \alpha_{2}$ as sketched in Fig. 1.

\subsection{Stability analysis}

In $\mathrm{KF}$, the stability of an originally straight shoreline exposed to obliquely incoming waves was studied for a constant forced wave climate. These results can be expanded to varying wave climates by superposition of the growth rates from the model runs with the constant wave climates. This is justified in the linear regime.

The varying wave climates are reduced in this investigation to contain just 4 different directions as shown in Fig. 1, i.e.:

$-90^{\circ}<\Delta \alpha_{1}<-45^{\circ}<\Delta \alpha_{2}<0^{\circ}<\Delta \alpha_{3}<45^{\circ}<\Delta \alpha_{4}<90^{\circ}$.

There are no differences between positive or negative angles for a sinusoidal undulation, so only the first two intervals $\left(\Delta \alpha_{1}\right.$ and $\left.\Delta \alpha_{2}\right)$ are used in the following. The growth rate representative for the first

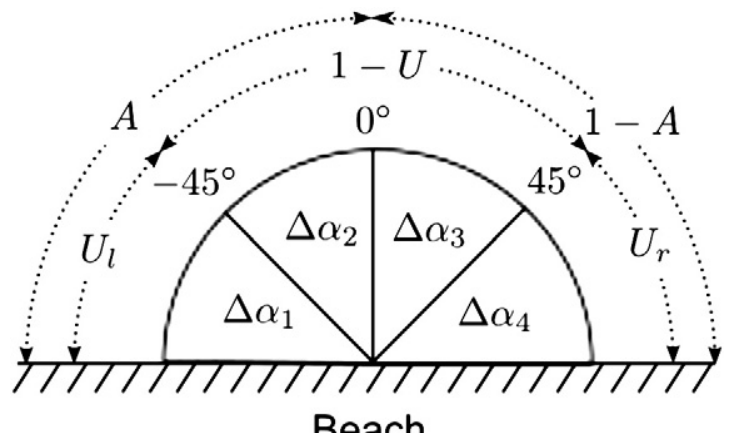

Fig. 1. The sketch showing the definition of $U=U_{l}+U_{r}$ and $A$ as well as the four wave direction intervals. interval, $\sigma_{u}$, is found by averaging the growth rate over the mean wave direction, $M W D$, i.e.:

$\sigma_{u}=\frac{1}{45^{\circ}} \int_{M W D=-90^{\circ}}^{M W D=-45^{\circ}} \sigma d(M W D)$

and likewise for the second interval:

$\sigma_{s}=\frac{1}{45^{\circ}} \int_{M W D=-45^{\circ}}^{M W D=-0^{\circ}} \sigma d(M W D)$

In Fig. 2, $\sigma_{u}$ and $\sigma_{s}$ is shown together with $\sigma\left(M W D=30^{\circ}\right)$ and $\sigma\left(M W D=60^{\circ}\right)$ with model parameters set according to Table 1 and a Manning number of $45 \mathrm{~m}^{1 / 3} / \mathrm{s}$. It is seen that the average growth rate for the first interval is well represented by the growth rate found using a constant $M W D=60^{\circ}$, similarly the average growth rate for the second interval is well represented by the growth rate found using a constant $M W D=30^{\circ}$. This shows that the initial development of the shoreline can be described by a representative single wave direction instead of the sum of many different wave directions.

The growth rate can now be found for different values of the parameter $U$ (the fraction of waves coming from the unstable wave regime), as:

$\sigma(U)=U \cdot \sigma_{u}+(1-U) \cdot \sigma_{s}$

The result depicted in Fig. 3 shows that for decreasing $U$ the length of the most unstable undulation increases. This is in line with the results from KF because a decrease in $U$ is equivalent of decreasing the mean wave direction from around $60^{\circ}$ towards $45^{\circ}$. Further, it is seen that instability requires $U>0.6$ for the tested undulation lengths. This is in contrast to Ashton and Murray (2006b) who found the criteria for instability to be $U>0.5$. The main reason for this discrepancy is that shoreline curvature is ignored in the study by Ashton and Murray (2006b) which increases the range of instability.

\subsection{Further evolution}

In this section, the KF shoreline evolution model is used to simulate the evolution of shoreline undulations subject to changing wave climates. Only the mean wave direction is changed during the simulation according to the specified $U$ and $A$ parameter for each simulation while the wave height, wave period etc are kept constant. The implementation of the changing wave climate is explained in the following.

\subsubsection{Implementation of changing wave climate}

The procedure used is as follows: Each time the mean wave direction is changed in the simulation, a random number between 0 and 1 is generated, if the number is larger than $U$ then a direction from the stable wave regime is chosen, if the number is smaller than $U$ a wave direction from the unstable wave regime is chosen. A second random

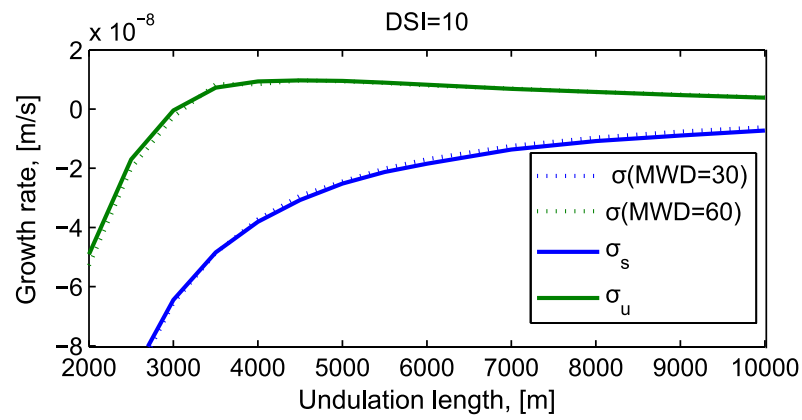

Fig. 2. The growth rate, $\sigma$ for mean wave direction of $30^{\circ}$ and $60^{\circ}$ together with the average growth rate for the first, $\sigma_{u}$, and second, $\sigma_{s}$, wave direction intervals. 
Table 1

Model parameters used when not stated otherwise.

\begin{tabular}{lll}
\hline Parameter & Symbol & Values \\
\hline Wave parameters: & & \\
Significant wave height & $H_{s}$ & $1 \mathrm{~m}$ \\
Mean wave direction & $M W D$ & $60^{\circ}$ \\
Directional Spreading Index & $D S I$ & 10 \\
Peak wave period & $T_{p}$ & $5 \mathrm{~s}$ \\
Breaking wave parameter & $\gamma$ & 0.8 \\
& & \\
Sediment parameters: & & 0.4 \\
Sediment porosity & $p$ & $0.2 \mathrm{~mm}$ \\
Sediment grain diameter & $d_{50}$ & 1.1 \\
Sediment grain grading coef. & $\sigma$ & 2.65 \\
Relative sediment density & $s$ & 0.05 \\
Critical shield parameter & $\theta_{c}$ & \\
\hline
\end{tabular}

number is generated to choose which side the wave should come from.

In the numerical model, a change in the mean wave direction between two morphological time steps means that the longshore current must be accelerated or decelerated, which takes time. Therefore, the model runs a lot faster when the mean wave direction is not changed too frequently. This means that an approach where the mean wave direction is changed at every new morphological time step is very time consuming in the present model.

Therefore, a faster approach is used in the following. Instead of picking a random wave direction in each interval, a representative wave direction for each interval is chosen. This choice is made based on the growth rates shown in Fig. 2. This figure shows that the average growth rate for direction interval $\Delta \alpha_{4}$ is well represented by the growth rate for $M W D=60^{\circ}$, and that the average growth rate the direction interval $\Delta \alpha_{3}$ is well represented by the growth rate for $M W D=30^{\circ}$. This indicates that in the linear regime there will be very little difference between using a random wave direction in the interval $45^{\circ}-90^{\circ}$ at every new morphological time step, and using $60^{\circ}$ for all the directions that fall in this interval. In the same way, using $M W D=30^{\circ}$ instead of a random mean wave direction between $0^{\circ}$ and $45^{\circ}$ should give almost the same result in the linear regime. It is well known from i.e. Hanson (1989) that this is not the case in the non-linear regime, but it is a necessary simplification due to the long simulation times of the present model. Lastly, a time step, $\Delta T_{M W D}$, is introduced; it determines how often a new value for the mean wave direction is computed.

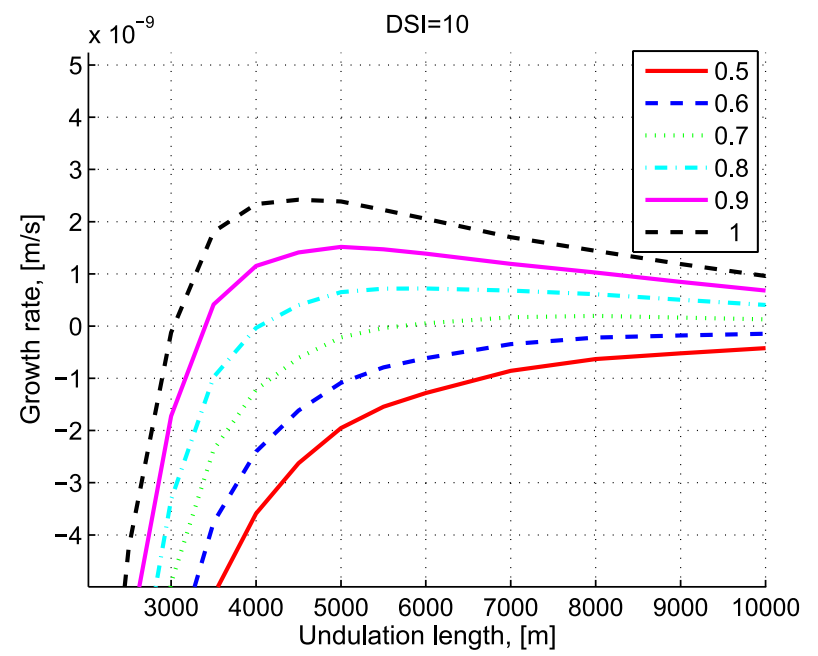

Fig. 3. The growth rate as function of undulation length for different fractions of oblique waves, $U$.

\subsubsection{Evolution of shoreline undulations}

In this section, we study the further evolution of an originally sinusoidal shoreline perturbation under impact from a varying wave climate. All wave parameters and model parameters are kept constant except the wave direction, the other model parameters are set according to Table 1 . Model simulations are made for the combinations of $U$ and $A$ shown in Table 2 all for $\Delta T_{M W D}=100$ days. Some of them are also run for $\Delta T_{M W D}=10$ days. The results are presented in the following.

The evolution of the width and the total width of the shoreline undulation (defined in Fig. 4) for the simulations is shown in Fig. 5: the width decreases with $U$, whereas the width nearly does not depend on the $A$ parameter.

For $U=0.8$ an equilibrium has not yet been reached in any of the simulations. From result of the simulation with $U=0.8$ and $A=1$ it seems like it may never happen; due to the large value of $\Delta T_{M W D}=$ 100 days, the stochastic behavior of the mean wave direction causes the width of the undulation to fluctuate around a certain width with a large amplitude of the fluctuation. Adding the wave directions in the $U=0.8$ and $A=1.0$ run gives $M W D^{*}=0.8 \cdot 60^{\circ}+0.2 \cdot 30^{\circ}=54^{\circ}$, thus the simulation can be compared with the simulation from part 1 with $M W D=55^{\circ}$. It is then seen that there is a large difference in the simulated evolution: the undulation with the constant wave climate grows much faster and to a greater width than the simulation with the varying wave climate, even if their average wave directions are within one or two degrees of each other. This illustrates the importance of the varying wave climate for the time scale and the final width.

The effect of changing $\Delta T_{M W D}$ on the evolution of the shoreline shape is seen in Fig. 6. It is observed that a spit is formed in both simulations; the first spit, which forms in both simulations, reconnects to the shoreline and therefore disappears again. The development of the spit is much faster in the simulation with the large value of $\Delta T_{M W D}$.

The effect of changing $\Delta T_{M W D}$ on the width of the undulation is seen in Fig. 7, where four cases are shown for $A=0.8$ and 0.9 and $\Delta T_{M W D}=10$ and 100 days. $U=1$ for in all cases. Not surprising a larger variability is seen on the width of the undulation for the larger $\Delta T_{M W D}$ because when $\Delta T_{M W D}$ is increased, the morphology is allowed to develop away from the time averaged shape for a longer period of time before the forcing is changed forcing the shape back towards the time averaged shape.

\subsection{Evolution of multiple undulations}

Until now, only the evolution of one sinusoidal undulation in a periodic domain has been studied. This section considers the case of how undulations with different amplitudes and wave lengths will interact. We study multiple undulations in a periodic domain by running the model on an initial shoreline described by:

$y=\sum_{i=1}^{i=n} h a_{i} \sin \left(i \frac{2 \pi}{L} x\right) \pm h b_{i} \sin \left(i \frac{2 \pi}{L} x\right)$

Table 2

Overview of the main simulations made with changing wave climates. "NS" means that no spit is formed during the computation. "S" means that a spit is formed during the computation and - means that this combination of $U$ and $A$ was run not.

\begin{tabular}{lllllllll}
\hline & \multicolumn{7}{c}{$A$ (fraction of waves from left) } \\
\cline { 3 - 9 } & & 0.5 & 0.6 & 0.7 & 0.8 & 0.9 & 1 \\
\hline \multirow{2}{*}{$U$ (fraction of unstable waves) } & 0.8 & - & - & - & NS & NS & NS \\
& 0.9 & - & - & - & NS & S & S \\
& 1.0 & NS & NS & NS & S & S & S \\
\hline
\end{tabular}




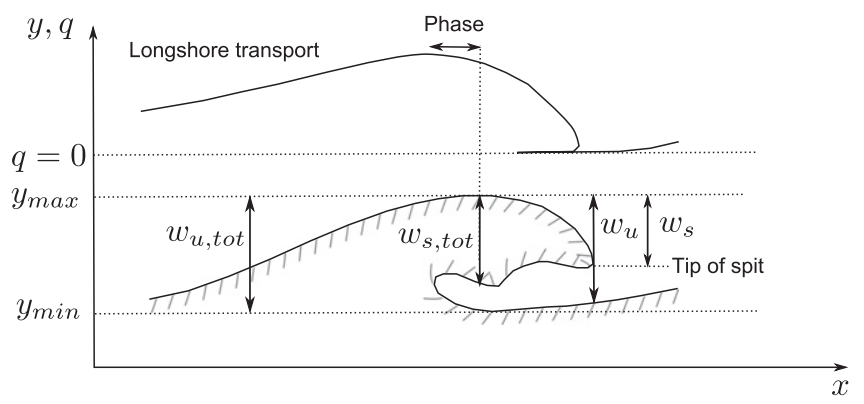

Fig. 4. Definition of the undulation width: $w_{u}$, total width: $w_{u, t o t}$, spit width: $w_{s}$, total spit width: $w_{s, t o t}$ and Phase.

where $h=10 \mathrm{~m}$ is the initial amplitude of all components, $a_{i}$ is a random number between 0 and $1, b_{i}=\sqrt{1-a_{i}^{2}}, L=20,000 \mathrm{~m}$ and \pm is randomly plus or minus. This gives an initial shoreline with the coastal volume distributed evenly on the $n$ longest lengths which can be described in the domain. Here $n=10$ is used, so the lengths are between $2000 \mathrm{~m}$ and $20,000 \mathrm{~m}$.

For the case of $U=1.0$ and $A=0.5$ the evolution of the amplitude of the 10 longest components is shown in Fig. 8 and the time stack of the evolution is depicted in Fig. 9. In the beginning of the evolution, the fastest growing components are $L=4000 \mathrm{~m}$ and $L=5000 \mathrm{~m}$, while $L=3333 \mathrm{~m}$ is the shortest component which grows in the simulation. As the amplitudes increase, the amplitudes of the undulations with lengths $L=4000$ and $L=3333 \mathrm{~m}$ start decreasing, and the $L=6667 \mathrm{~m}$ grows just as fast as the $L=5000 \mathrm{~m}$ towards the end of the simulation.
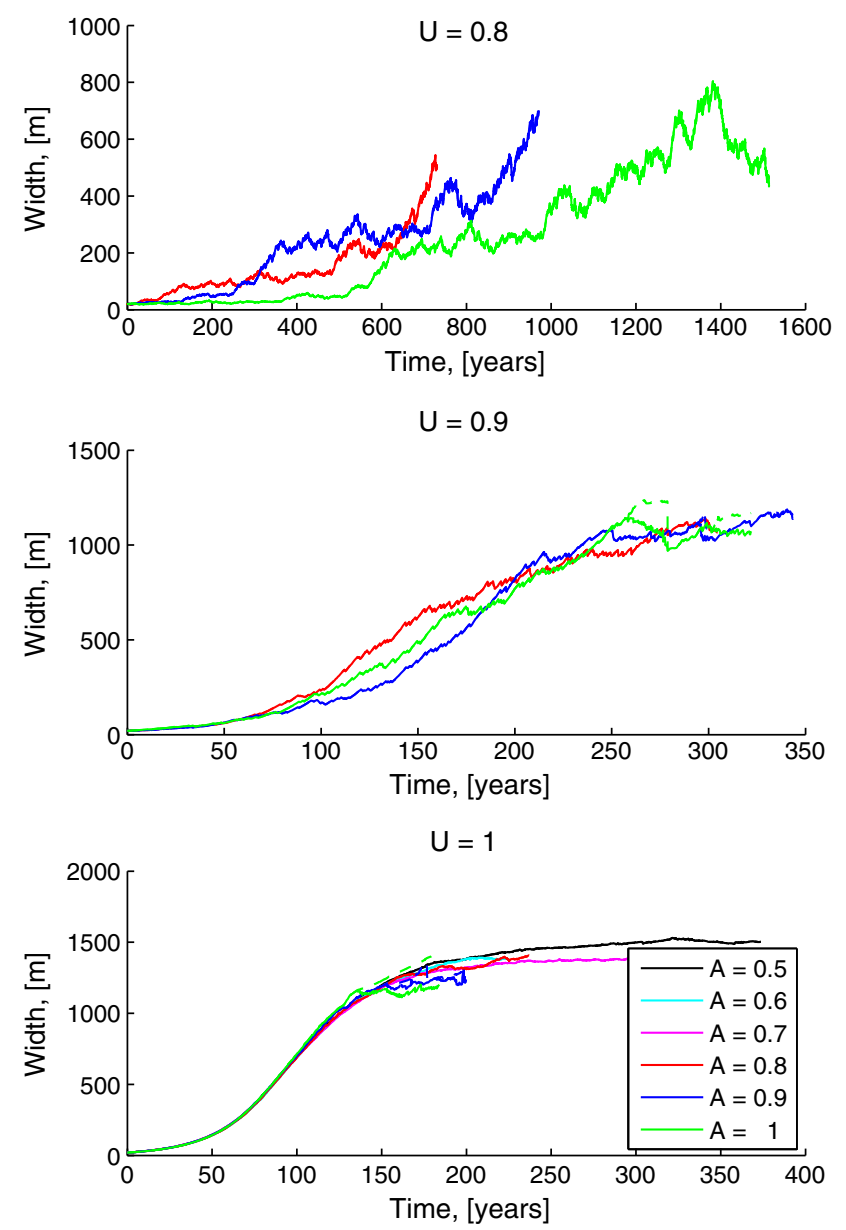

Fig. 5. The evolution of undulation width for simulations from Table 2. Dashed lines are total width, $w_{u, t o t}$ and full lines are width $w_{u}$, (defined on Fig. 4).
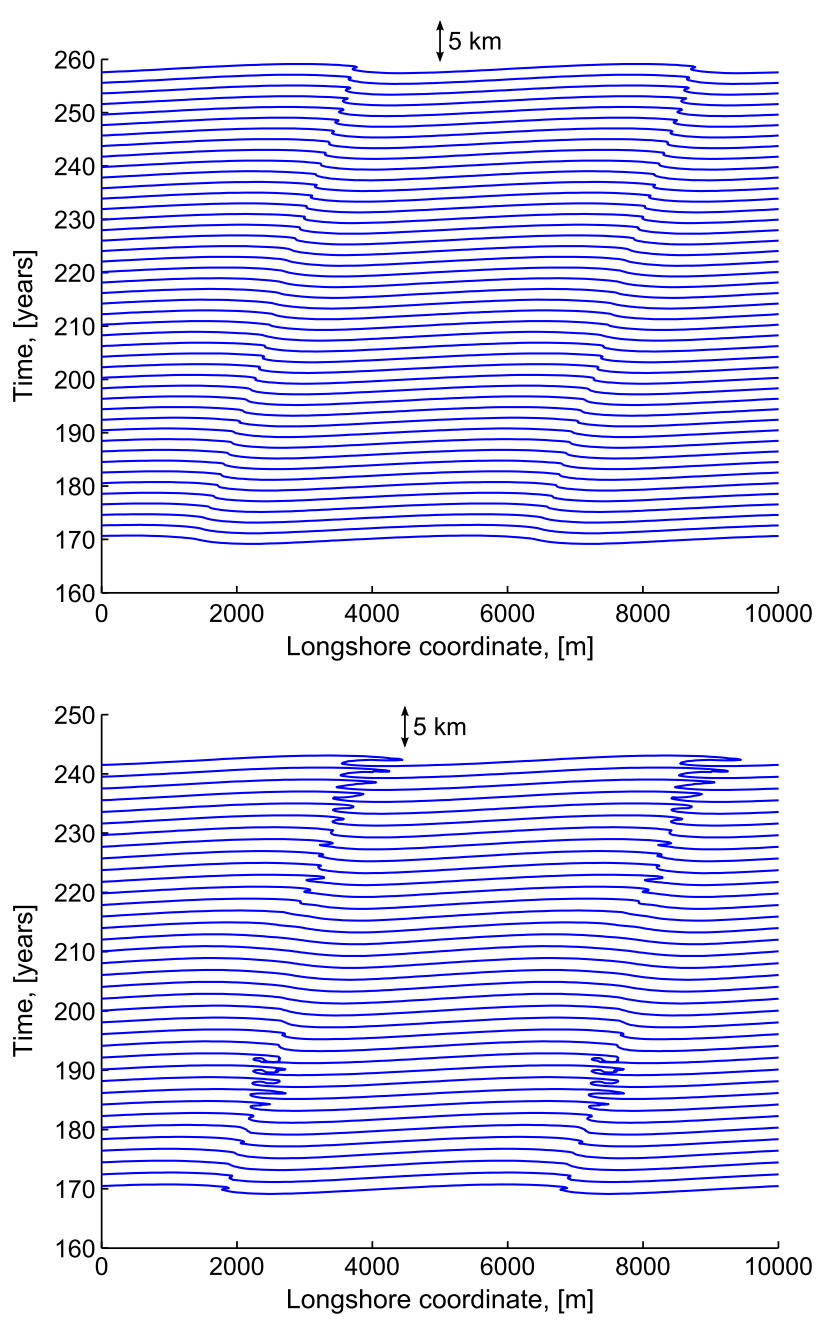

Fig. 6. Impact of the time before changing wave direction. Top: Time stack of the shoreline evolution for the simulation with $U=1, A=0.8$ and $\Delta T_{M W D}=10$ days. Bottom: Time stack of the shoreline evolution for the simulation with $U=1, A=0.8$ and $\Delta T_{M W D}=100$ days.
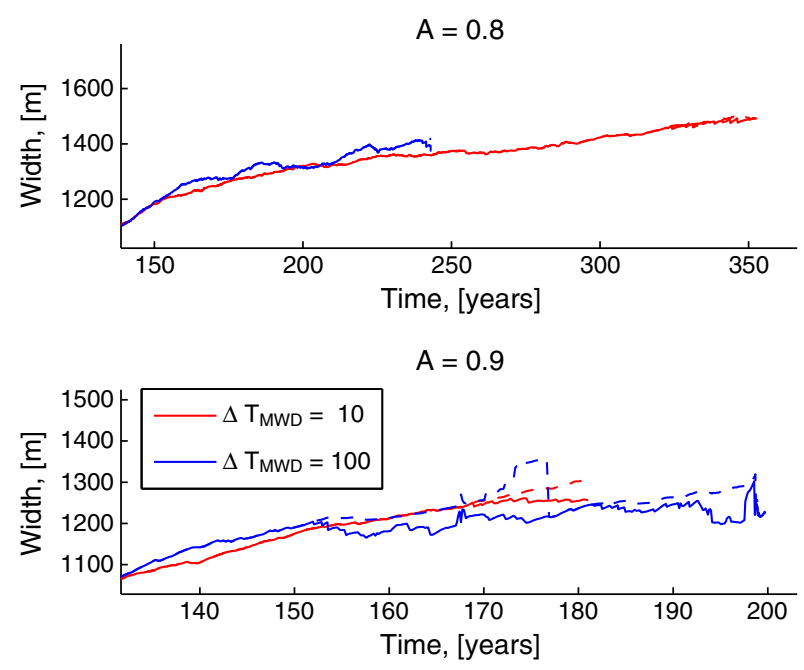

Fig. 7. The evolution of undulation width for simulations with $U=1$ and different $A$ and $\Delta T_{M W D}$ (in days). Dashed lines are total width, $w_{u, t o t}$ and full lines are undulation widths, $w_{u}$ (defined on Fig. 4). 

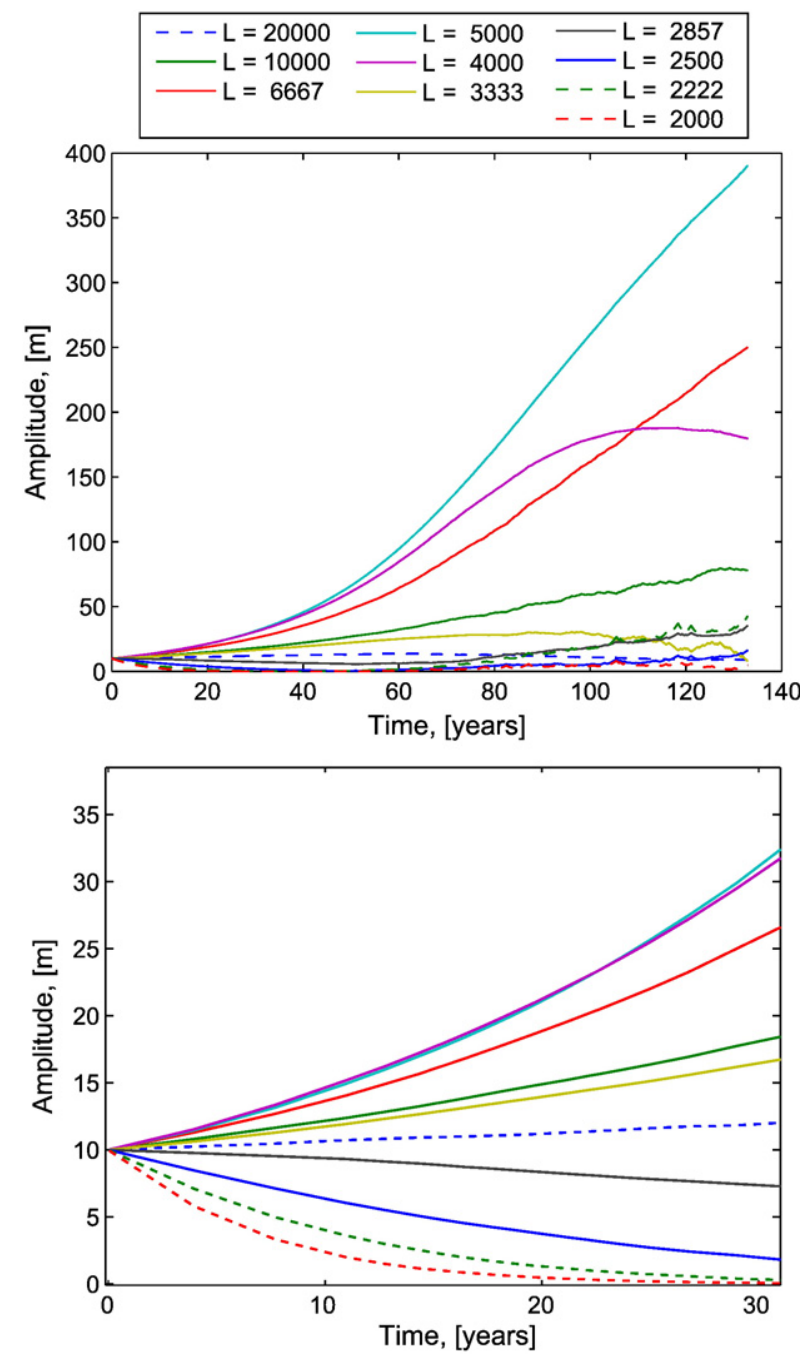

Fig. 8. Top: Evolution of the amplitude of the 10 longest waves lengths present in the simulation with a total domain length of $L=20,000$ and wave climate parameters $A=$ 0.5 and $U=1.0$. Bottom: Blow-up of the top panel.

On the time stack in Fig. 9, it is seen how the shorter undulation merge with longer undulations, thereby making the longer undulation even longer. It is noted this coarsening of the shoreline undulations towards longer and longer undulation length looks very similar to the process described by Ashton and Murray (2006b) who found the coarsening to be related to the shadow effect where one shoreline undulation shadows the down drift undulation from the incoming waves thereby limiting its growth. In the present case, the coarsening happens because as the width of the undulations grows, the length of the most unstable undulation increases without any shadow effect. Thereby, slightly longer undulation will grow faster and begin to dominate. The most unstable length grows when the width continues to grow. This process actually continues until only one undulation is present in the periodic domain.

\subsection{Types of shoreline undulations in a varying wave climate}

The shape and dimensions of the longshore shoreline undulations depend heavily on the incoming wave conditions. Three types of shoreline shapes was described in KF regarding waves from one direction: undulation with no spit, undulation with nearly shore-parallel spit and undulation with reconnecting spit. The reconnecting spit is a spit, which reconnects with the shoreline, after which a new spit is created.

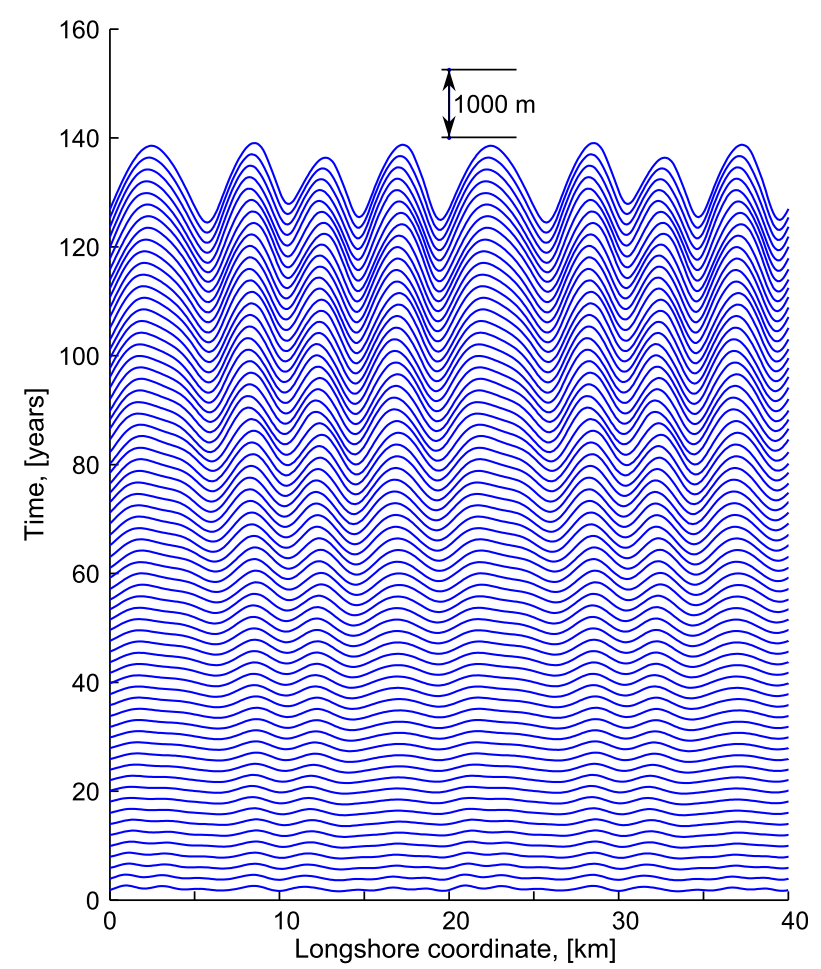

Fig. 9. Time stack of the evolution of the shoreline for the simulation with a domain length of $L=20,000 \mathrm{~m}$ and wave climate parameters $A=0.5$ and $U=1.0$.

For the case of varying wave climate all three possible shapes are formed: When all waves are coming from the unstable wave regime, i.e. for $U=1$, a spit is formed when waves approach mainly from the left or right, i.e. for $A=0.8,0.9$ and1.0. No spit is formed for incoming waves from both directions, $A=0.5,0.6$ and 0.7 . The present analysis predicts that with $30 \%$ or more of the wave energy stemming from two opposite directions, the formation of a spit is prevented.

When the fraction of waves coming from the unstable wave regime is reduced to $U=0.9$, the formation of a spit is prevented already for $A=0.8$, and for $U=0.8$ the spit formation is prevented even for $A=1$. Waves from the stable regime are better at inhibiting the development of spits, than waves from the opposite direction. It is noted that the length of the undulation was kept constant at $L=$ $5000 \mathrm{~m}$, when the $U$ parameter was changed, which potentially could explain part of the suppression of the spit development: as seen in $\mathrm{KF}$, if the undulation length is much shorter than the most unstable undulation length, no spits form even in the case of constant wave forcing. However, from the stability analysis, Fig. 3,it is found that for $U=0.8$, the most unstable length is $L=5500 \mathrm{~m}$, thus within $10 \%$ of the $5000 \mathrm{~m}$ which was used. For $U=0.9$ the most unstable length is exactly the one which was used, $L=5000 \mathrm{~m}$.

\section{Comparisons with field observations}

The aim of this section is to compare the predictions from the numerical model with the size and shape of shoreline undulations on two naturally occurring shorelines based on the measured wave climate, the sediment size and the coastal profile at each location. The first shoreline is located on the west coast of Namibia, and this has been chosen because it certainly falls into the unstable regime. Further, it is characterized by its large dimensions: the length of the undulations is about $60 \mathrm{~km}$. Finally, we have enough data to make a comparison with the model. This is also the case for the second shoreline selected, which is located on the west coast of Denmark. This 
location has been chosen, because it is exposed to oblique waves, where we are in the transitional regime in between a stable and an unstable coastline. Further, this shoreline is characterized by smaller undulations with a typical wavelength of only a few kilometers.

\subsection{Methodology}

The stability analysis is used to determine the most unstable length of the shorelines from the local wave climate, bathymetry and shoreline orientation, next the evolution model is used to describe the further evolution of the shoreline undulations.

Because the waves are used to drive the longshore sediment transport and this longshore sediment transport historically is taken to depend on the wave height cubed (see e.g. Komar and Inman (1970)), the average wave conditions are found by weighting the wave conditions similarly.

The average mean wave direction is found as:

$W x=\left(H_{s}\right)^{3} \cos \left(90^{\circ}-M W D\right)$

$W y=\left(H_{s}\right)^{3} \sin \left(90^{\circ}-M W D\right)$

$\overline{M W D}=90^{\circ}-\tan ^{-1}\left(\frac{W y}{W x}\right)$

where $H_{s}$ is the significant wave height and MWD is the mean wave direction and $\overline{M W D}$ is the average mean wave direction.

The average significant wave height is found as:

$H_{s m}=\left(\overline{\left(H_{s}\right)^{3}}\right)^{1 / 3}$

where $H_{s m}$ is the mean significant wave height, $H_{s}$ is the significant wave height.

Finally, the average peak wave period is found as:

$T_{p m}=\frac{\sum\left(\left(H_{s}\right)^{3} T_{p}\right)}{\sum\left(H_{s}\right)^{3}}$

where $T_{p m}$ is the mean peak wave period and $T_{p}$ is the peak wave period.

The model is based on an average cross-shore coastal profile, i.e. the same coastal profile is used along the entire shoreline in the model. When no measurements of the coastal profile exist, it is chosen to use a Dean type coastal profiles, such that the water depth from the shore to the closure depth is given by:

$z=A_{b} \cdot y^{m}$

where $z$ is the vertical coordinate of the bathymetry and $y$ is the cross-shore coordinate of the bathymetry. $A_{b}$ is the steepness of the profile and $m=2 / 3$. Dean (1991) suggested $A_{b}$ to depend on the grain size, but instead we have chosen to determine $A_{b}$ from the measured profiles using either sea maps or bathymetric measurements. Beyond the closure depth, the water depth is taken as constant in the model.

\subsubsection{Closure depth}

In the present work, the closure depth is the depth to which the shoreline undulations can be felt on the bathymetry, this depth does not have to be the same depth as the original definition by Hallermeier (1981). The reason for this difference in the definition is that Hallermeier is strictly concerned with surf-zone processes and time scales of year to decades, whereas we are concerned with describing the evolution of the shoreline on a time scale of decades to centuries or even longer. On these longer time scales, shoreline features can impact the bathymetry further off-shore. One example of this is the case of a growing spit such as the Skaw spit in the north of Denmark, (see Kaergaard and Fredsoe (2013a) or Petersen (1991)). The Skaw spit is growing in an area where the water depth is $80-100 \mathrm{~m}$, but the depth of closure as defined by Hallermeier is only around $10 \mathrm{~m}$, and yet we can observe the spit on the $50 \mathrm{~m}$ depth contour.

\subsection{The west coast of Namibia}

The undulations on the west coast of Namibia are depicted in Fig. 10. Each is around $60 \mathrm{~km}$ long and between 10 and $12 \mathrm{~km}$ wide. Down drift spits are clearly observed attached to the crest of the undulation on the two northerly undulations; on the most southerly there are indications of an earlier existing spit, from the very light colored areas which indicate that they have been covered with water in a historic embayment. The embayments between the spits and the shoreline on the northerly undulations are seen filled up with sediment, probably from aeolian sediment transport originating from the dune field which is so large that the town at Walvis Bay needs protection from the drifting sand, Leroux (1974).

The literature discussing these undulations is limited, however, the spit on the most northerly undulation (near Walvis Bay) has been studied earlier by Elfrink et al. (2003) and by Schoonees et al. (1998). Elfrink et al. (2003) focused on reasons for erosion on the spit. The harbor inside Walvis Bay is the most important harbor in $\mathrm{Na}-$ mibia and it is protected from the ocean waves by the spit, thus erosion of the spit is a serious problem. The study suggests that the erosion of the spit is due to a change in the wind direction and therefore wave direction to a more southern direction. This suggested change in wave direction promoted the growth of new spits further up drift, thus starving the original spit of sediment and thereby leading to erosion on the old spit. The spit is estimated to grow approximately $15 \mathrm{~m} /$ year and the yearly longshore sediment transport is estimated to be $1 \mathrm{M} \mathrm{m}^{3} /$ year.

Hughes et al. (1992) studied the vulnerability of Walvis Bay to rising sea levels. The migration rate of the spit was estimated to be $17 \mathrm{~m} / \mathrm{year}$ from old photos and sea maps and a CSIR (Council for Scientific and Industrial Research, South Africa) report is cited, where the longshore sediment transport rate was estimated to be $2 \mathrm{M} \mathrm{m}^{3} /$ year on ocean side shoreline of the spit protecting Walvis Bay.

\subsubsection{Available data}

3.2.1.1. Wave data. The off-shore wave climate is available both in Elfrink et al. (2003) at a water depth of $137 \mathrm{~m}$ and in Bosman and Joubert (2008) at a water depth of $153 \mathrm{~m}$. Regarding the significant wave height and the mean wave direction the two sources are consistent, but there is a large difference in the peak wave period. In Bosman and Joubert (2008), the most common peak wave period is $12-14 \mathrm{~s}$, whereas Elfrink et al. (2003) suggests it to be $6-8 \mathrm{~s}$. In both cases the wave climate is based on hind cast modeling. In connection with the work presented in Elfrink et al. (2003) an ADCP was deployed close to the shoreline at Pelican Point in $30 \mathrm{~m}$ water depth, the ADCP was in the water from 27-10-2001 to 13-11-2001; the measured time series of the mean wave period, the zero crossing wave period and the peak wave period is shown in Fig. 11. From the figure, it is observed that the peak wave period almost always lies between 10 and $14 \mathrm{~s}$ whereas the mean wave period and the zero crossing wave period is between 5 and $8 \mathrm{~s}$. This indicates a wave frequency spectrum with two peaks, i.e. with two different wave components present; one swell component with a period around $12 \mathrm{~s}$ and a wave component generated by the local wind with a period around $6 \mathrm{~s}$. Most of the time the swell component contains most of the wave energy, leading to a peak wave period around $12 \mathrm{~s}$, however, sometimes the peak wave period drops to the mean wave period indicating that the swell component is weak at those times. The measured peak wave period indicates that the peak wave periods stated 

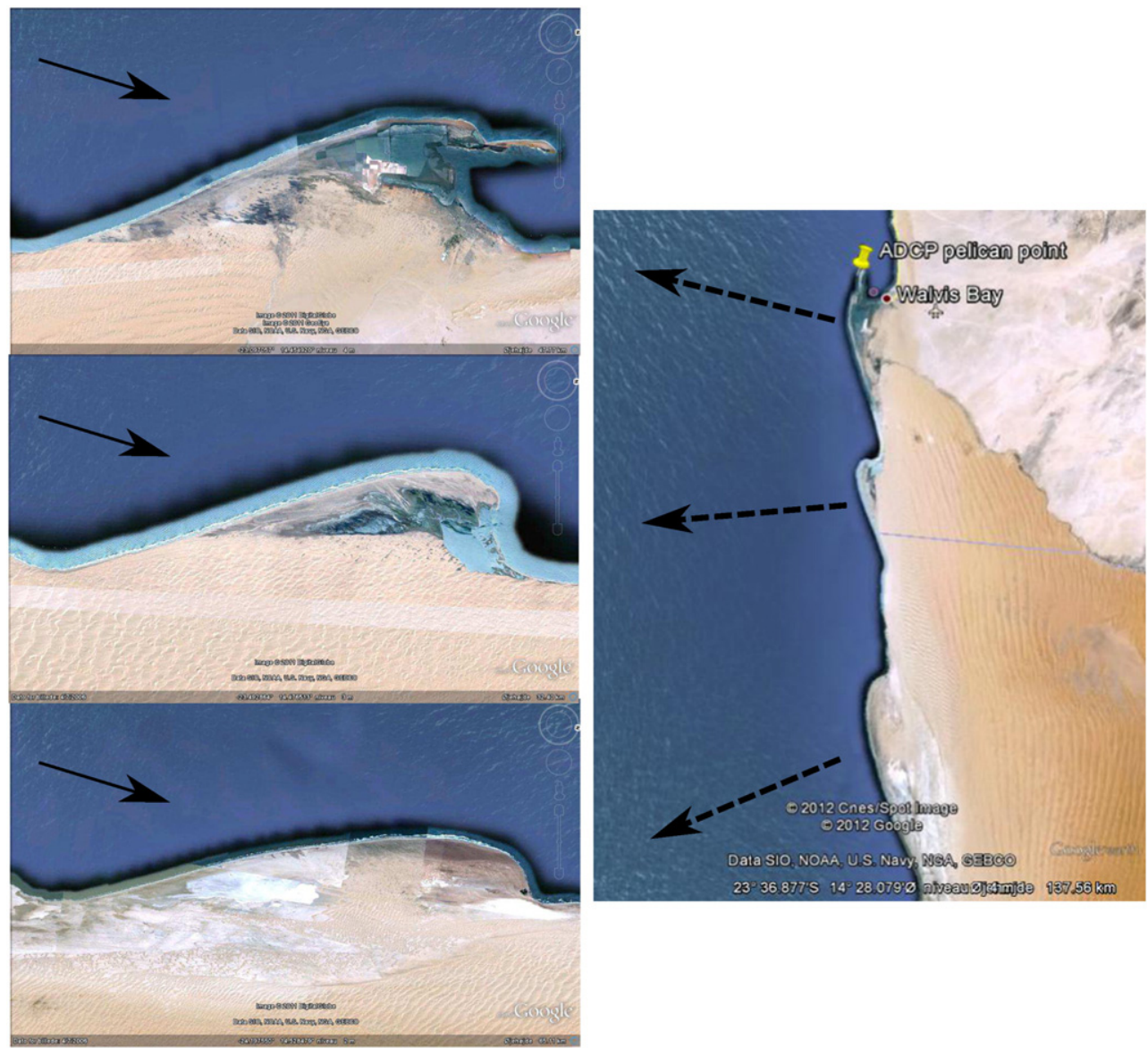

Fig. 10. Overview and close-ups of the undulations on the west coast of Namibia. The main direction of the incoming waves is shown with the arrow for each undulation.

in Bosman and Joubert (2008) are correct, and therefore this wave climate, depicted in Fig. 12, is used in the present study.

Fig. 12 shows that nearly all waves offshore are in a very narrow angle-window around $200^{\circ}$, so in this case it is not necessary to consider waves approaching from various directions. The averaged wave conditions from the wave climate are found to be: Average mean wave direction, $\overline{M W D}=203^{\circ}$, average significant wave height $H_{s m}=2.4 \mathrm{~m}$ and average peak wave period $T_{p}=12.7 \mathrm{~s}$. The directional spreading index is set to 10 .

Using Snell's Law and linear wave theory the mean direction of off-shore wave direction can be transferred to smaller water depths. The shoreline normal direction with North is taken to be $273^{\circ}$, thus the angle between the off-shore mean wave direction and the shoreline angle is $70^{\circ}$. Due to wave refraction from $153 \mathrm{~m}$ of water depth the angle is reduced to $57^{\circ}$ at a depth of $50 \mathrm{~m}$; at $40 \mathrm{~m}$ it is $52^{\circ}$ and at $30 \mathrm{~m}$ it is $45^{\circ}$.

3.2.1.2. Sediment size and coastal profile. The sediment size is constant in the model domain and is taken from Schoonees et al. (1998) who found a median sediment size of $0.35 \mathrm{~mm}$ close to Pelican Point which is the tip of the spit at Walvis Bay. The coastal profile is assumed to be a Dean profile and the steepness is found from the map shown in Fig. 13, it is observed that in the trough of the

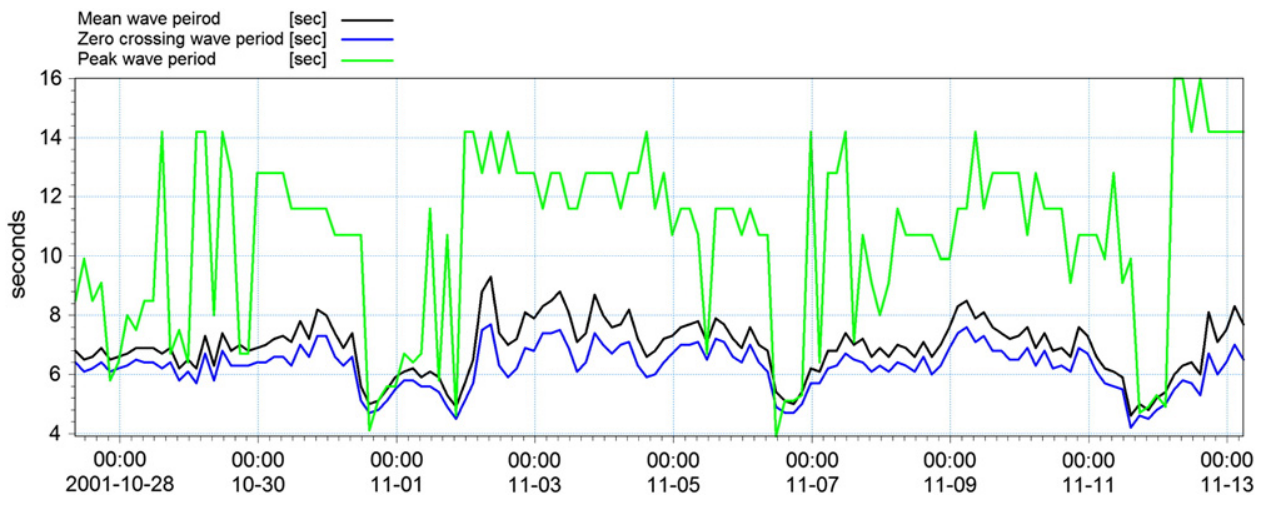

Fig. 11. The wave periods measured at Pelican Point 


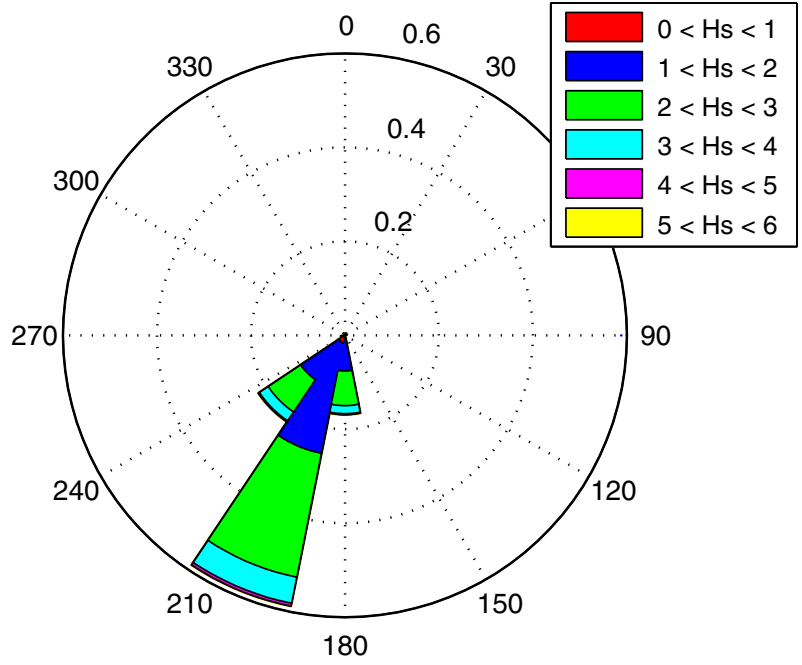

Fig. 12. The off shore wave climate west of Namibia, from Bosman and Joubert (2008).

undulation the $30 \mathrm{~m}$ depth contour is $\approx 4.5 \mathrm{~km}$ off-shore, whereas at the crest of the undulation the $30 \mathrm{~m}$ contour is $\approx 2 \mathrm{~km}$ off-shore. In Fig. 14, two Dean profiles are drawn with a steepness equal to 0.2 and 0.12 respectively. It is seen that these intersect the $30 \mathrm{~m}$ depth contour at around 2 and $4 \mathrm{~km}$ offshore corresponding to the observed values found on the sea map; thus these two steepnesses are investigated in the KF-model together with the average of 0.16 . It is noted that on the spit near Pelican Point the coastal profile is steeper and further that the coastal profile is by no means constant along the entire coastline.

\subsubsection{Impact of depth of closure}

As outlined in KF, the depth of closure is an important parameter for the prediction of the scales involved: the larger the depth of closure, the larger the most unstable length of the predicted undulation will be. In a field study, (Kaergaard et al., 2012), it is shown that the depth of closure is at least $4 H_{s}$, and usually we adapt this value.

However, from the sea map in Fig. 13 you can actually observe impact from undulations even at a water depth equal to $40 \mathrm{~m}$, so sediment transport at this water depth must be involved in the morphological interaction with the undulation. Assuming a peak wave period equal to $12.7 \mathrm{~s}$, bed sediment (diameter $=0.35 \mathrm{~mm}$ ) will be moved at this depth if $H_{s}$ exceeds $1.5 \mathrm{~m}$. The waves are larger than this more than $50 \%$ of the time.

\subsubsection{Stability analysis}

For the stability analysis the parameters shown in Table 3 are kept constant, while varying the mean wave direction $\left(M W D=50^{\circ}, 55^{\circ}\right.$ and $\left.60^{\circ}\right)$, the steepness of the coastal profile $\left(A_{b}=0.12,16\right.$ and 0.2$)$ and the closure depth $\left(D_{\text {cld }}=30,40\right.$ and $\left.50 \mathrm{~m}\right)$.

The result of the stability analysis is shown in Fig. 15, where the most unstable undulation length is shown for the two flattest coastal profiles chosen. The most unstable undulation length is almost linearly dependent on the closure depth for all profile steepnesses and mean wave directions. The most unstable undulation length is around the observed value of $60 \mathrm{~km}$ for two realistic combinations of closure depth, profile steepness and mean wave direction, these are seen in Table 4 . For the steepest coastal profile $\left(A_{b}=0.2\right)$ all lengths were shorter than the observed. For the smallest closure depth, i.e. $D_{c l d}=$ $30 \mathrm{~m}$, the mean wave direction becomes $45^{\circ}$ which is just above the limit between the stable and the unstable wave regime, so this smaller depth is not analyzed further.

Both of the combination shown in Table 4 fit well with the averaged mean wave direction at their respective depths. The waves refract $\approx 5^{\circ}$ between 40 and $50 \mathrm{~m}$ water depth, and there is $5^{\circ}$ between the mean wave directions for the two combinations. So, when the coastal profile steepness is $A_{b}=0.16$ and when depth induced wave refraction is taken into account, the same most unstable undulation length comes out of the stability analysis for both $D_{c l d}=$ $40 \mathrm{~m}$ and $D_{\text {cld }}=50 \mathrm{~m}$.

We have also undertaken a stability analysis with a smaller depth of closure $=10 \mathrm{~m}$ together with shorter waves with a significant wave height of $2 \mathrm{~m}$, a peak wave period of $6 \mathrm{~s}$ and a mean wave direction of $55^{\circ}$. Using a profile steepness of 0.12 , the most unstable undulation length is $8 \mathrm{~km}$; increasing the profile steepness to 0.14 decreases the most unstable length to $6 \mathrm{~km}$.

On the location, large scale as well as shorter undulations (with a length of approximately $6 \mathrm{~km}$ ) have been observed, see also van den Berg et al. (2012). This might suggest that shorter undulations formed by less high waves forms one kind of undulations, while the larger waves are associated with the larger scale. In addition, the shorter undulations are mainly located in the troughs of the larger undulations. This part of the shore is partly sheltered by the larger undulations. This will cause a change the angle of approach of the waves hitting this part of the shore, and thereby the preferred wavelength of the undulations.

The mutual interaction between the shorter and longer undulations have not been included in this study, but probably the shorter ones may help to trigger the evolution of the larger ones, just like ripples trigger the formation of dunes in the fluvial environment, see Fourriere et al. (2010). In the ripple case, this implies an increase in bottom roughness to create dunes, but in our case, smaller undulations probably extend the shoreline impact on coastal profile further offshore in one or another way, which certainly needs to be investigated further.

\subsubsection{Shoreline evolution}

The evolution model has been run for the two combinations of coastal profile steepness, closure depth and mean wave direction shown in Table 4. All other parameters are kept constant with the same values as earlier.

The time stack of the shoreline evolution for Combination 1 (Table 4) is shown in Fig. 16 until the development of a spit, and in Fig. 17, the further development of a spit is followed. It is noted that it takes around 10,000 years before the formation of a spit. At this point the undulation has migrated $2 / 3$ of its own length in the alongshore direction.

The time stack of the shoreline evolution for Combination 2 (Table 4) is shown in Fig. 18 before the development of a spit, and in Fig. 19 after the development of a spit. For Combination 2, the spit development also happens between year 10,000 and year 11,000.

\subsubsection{Morphologic parameters}

Table 5 lists the undulation width, $w_{u}$, the spit width, $w_{s}$ (as defined on Fig. 4), the migration speed of the spit, $c$, and the longshore sediment transport rate, $q$, for the two combinations from Table 4 .

It is noted that both combinations have undulation widths between 13.5 and $15 \mathrm{~km}$. The observations show undulation widths in the range of $8-12 \mathrm{~km}$, thus the model slightly over-predicts the undulation width by $10-25 \%$.

The observed spits have widths ranging from 1 to $2.2 \mathrm{~km}$. So, Combination 2 fits the observations quite well regarding the spit width, whereas the spit for Combination 1 is minimum a factor 2 too wide.

The predicted migration rates of the spits are around $4 \mathrm{~m} /$ year for both Combinations 2 and 3. As mentioned in Section 2, the migration speed of the spit at Walvis Bay was found to be around $15 \mathrm{~m} / \mathrm{year}$ in Elfrink et al. (2003). The alongshore migration speed of the most southern undulation can be estimated using the position of the shipwreck "Eduard Bohlen" which sunk in 1909. Fig. 20 shows the position of the ship relative to the shoreline today. From the figure, the alongshore migration rate is estimated to be $13 \mathrm{~m} / \mathrm{year}$ assuming that the undulation migrates with unchanging form; if the width of the real undulation is growing the actual migration speed will be 


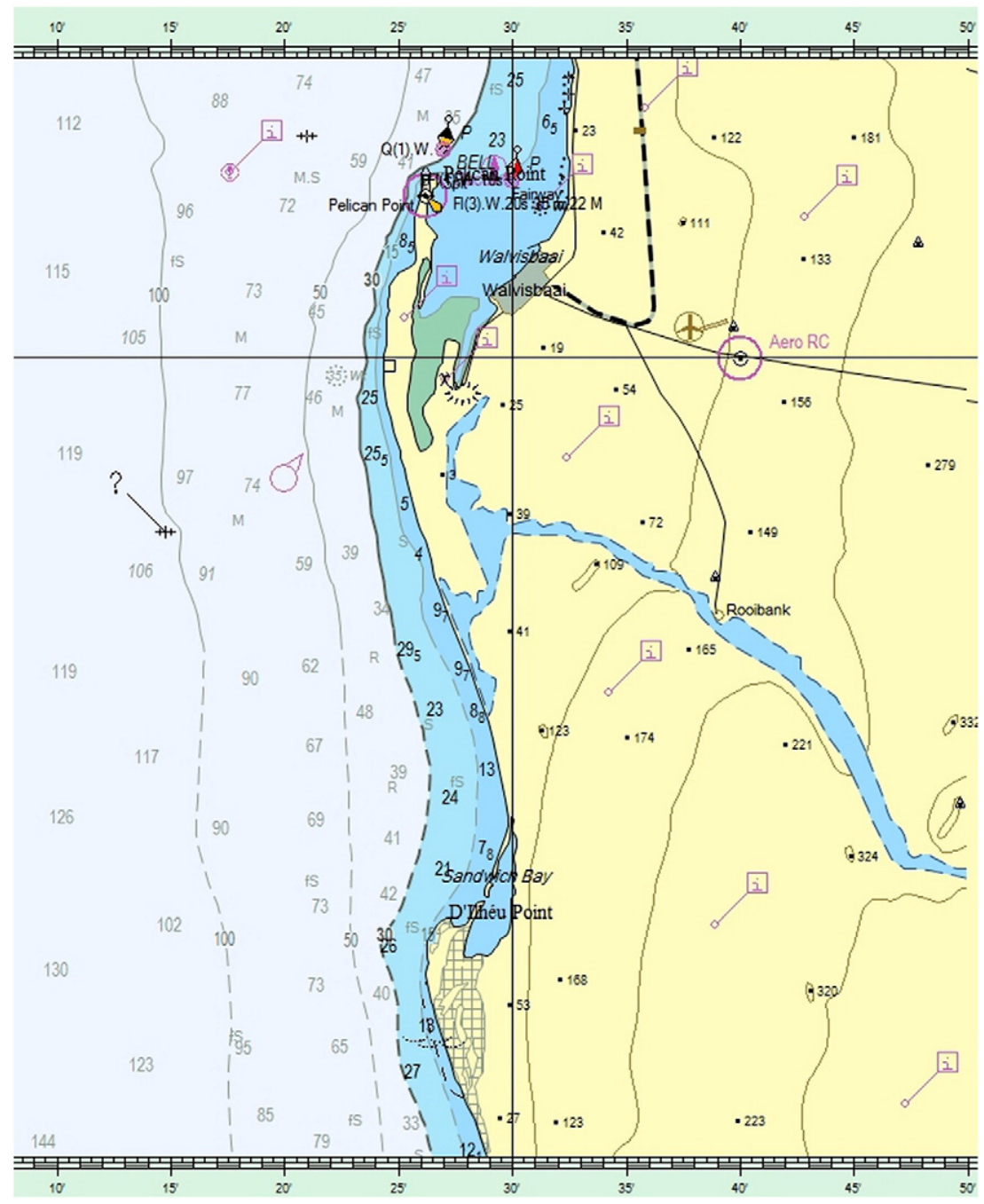

Fig. 13. Map showing a few off-shore contours, from C-Map. Depths are in meters.

smaller. So, it is found that the migration speeds in the model are between 20 and $33 \%$ of the observed migration speeds.

Comparing longshore transport rates from the model with the rates found in Elfrink et al. (2003) and in Hughes et al. (1992) which was $1 \mathrm{M}$ and $2 \mathrm{M} \mathrm{m}^{3} /$ year, we find that the transport rates in the model are right between these two observations.

The discrepancies between the predicted and observed migration rates could be explained partly by the fact that the model over predicts the undulation width and the width of the spit, and partly by the fact that the model assumes a constant coastal profile along an undulation, whereas the observed undulations clearly have steeper profiles at the crests and shallower profiles at the troughs of the undulations. If the undulation width is over-predicted by $50 \%$ in the model, the migration rate will be under-predicted by $66 \%$ if the longshore transport is modeled correct and the coastal profiles are also correct. It can be shown that (Kaergaard et al. (2012)) for an undulation migrating with unchanging shape, the longshore sediment transport is related to the local width of the undulation such that:

$q_{l}=D_{c l d} \cdot c \cdot w+q_{l, 0}$

where $w$ is the width, $c$ is the migration velocity of the undulation and $q_{l, 0}$ is a constant. Since $q_{l}, D_{c l d}$ and $q_{l, 0}$ are assumed constant, any change in $w$ must be countered by a change in $c$.
Further, if the profile locally is steeper at the crest and shallower at the trough of the undulation, the predicted migration velocity is increased because less sediment is required to fill up the profile.

However, these two geometrical effects cannot explain the whole discrepancy between the observed and modeled migration speeds, a possible further explanation is that the Bengula ocean current transports an unknown amount of sediment along the coastline which next to the sediment transport in the surf zone contributes to the migration of the undulations.

\subsection{The west coast of Denmark: Holmslands Tange}

The shoreline undulations at Srd. Holmslands Tange on the west coast of Denmark (Fig. 21) are described in detail in Kaergaard et al. (2012). The shoreline is quite straight and the undulations were found to be around $5 \mathrm{~km}$ long and $100 \mathrm{~m}$ wide.

\subsubsection{Available data}

Measurements of the wave climate, sediment size and coastal profiles have been compiled by the Danish Coastal Authorities (in Danish Kystdirektoratet).

The wave climate is measured at a number of places, for the present study, the wave climate measured at station 2041 (shown in Kaergaard et al., (2012)) is used. 


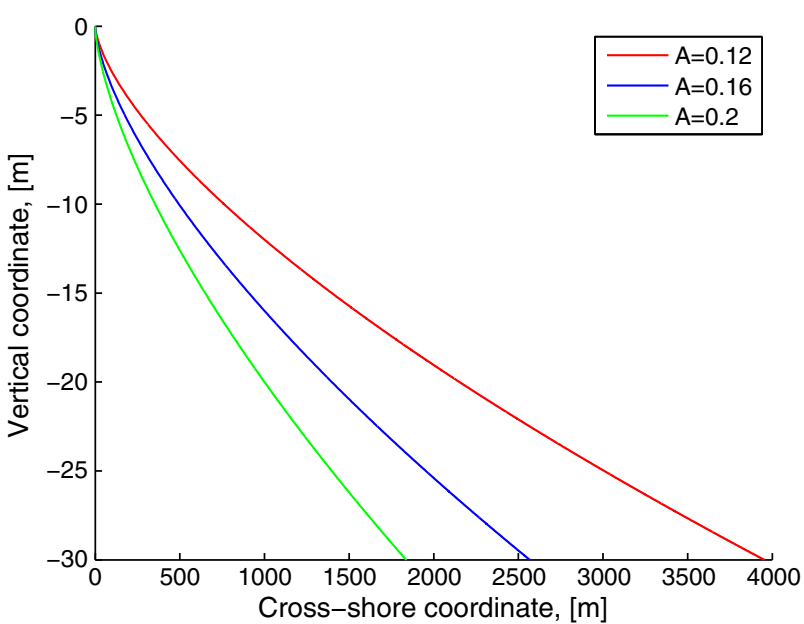

Fig. 14. Dean profile $\left(z=A_{b} y^{m}\right)$ for steepness parameters: $A_{b}=0.2, A_{b}=0.16$ and $A_{b}=$ 0.12 , all for $\mathrm{m}=2 / 3$.

The yearly average wave conditions are found to be: Average mean wave direction, $\alpha=305^{\circ}$, average significant wave height, $H_{s m}=1.8 \mathrm{~m}$ and average peak wave period, $T_{p m}=6.1 \mathrm{~s}$. The water depth at the station is $25 \mathrm{~m}$. The shoreline orientation is $263^{\circ}$, so the angle between the direction of the shoreline and the direction of the yearly mean wave direction is $42^{\circ}$. This is close to the critical angle giving maximum longshore transport, which means that if the waves refract before reaching the undulations they will be in the stable regime. The wave gauge which measured the data is located $14 \mathrm{~km}$ off-shore, which means that other processes than depth induced wave refraction can affect the waves on their way to the shoreline. These processes include wind forcing and current induced wave refraction, so a slight change can occur in the wave direction before reaching the shoreline; a parameter study is therefore made in the stability analysis to observe the effect of different wave directions.

The median grain size is $0.2 \mathrm{~mm}$ at Srd. Holmslands Tange (Kystdirektoratet (1999)).

The coastal profiles have been measured every $1 \mathrm{~km}$ at least every 5 years along the Danish west coast since the 1950s. Fig. 22 shows the average coastal profile based on the measured coastal profiles; only profiles from year 1970 to year 2000 and profile lines from 5700 to 5810 were used to make the mean. Three Dean profiles have also been draw for different steepness parameters.

The average coastal profile has a distinct shift in the steepness of the profile around $4.5 \mathrm{~m}$ water depth. According to Inman et al. (1993), this is the natural shape of coastal profiles due to the change in the wave conditions inside and outside the surf zone.

\subsubsection{Stability analysis}

Table 6 shows the parameters used for the stability analysis; the parameters not mentioned were set according to Table 1 . Two types of coastal profiles are used, a Dean profile with the steepness from the table, and the average measured profile shown in Fig. 22. For

Table 3

Parameters used for modeling the shoreline on the west coast of Namibia, the remaining model parameters are set according to Table 1.

\begin{tabular}{lll}
\hline Parameter & Symbol & Value \\
\hline Wave parameters: & & \\
Significant wave height & $H_{s}$ & $2.4 \mathrm{~m}$ \\
Directional Spreading Index & $D S I$ & 10 \\
Peak wave period & $T_{p}$ & $12.7 \mathrm{~s}$ \\
Sediment parameters: & & \\
Sediment grain diameter & $d_{50}$ & $0.35 \mathrm{~mm}$ \\
\hline
\end{tabular}
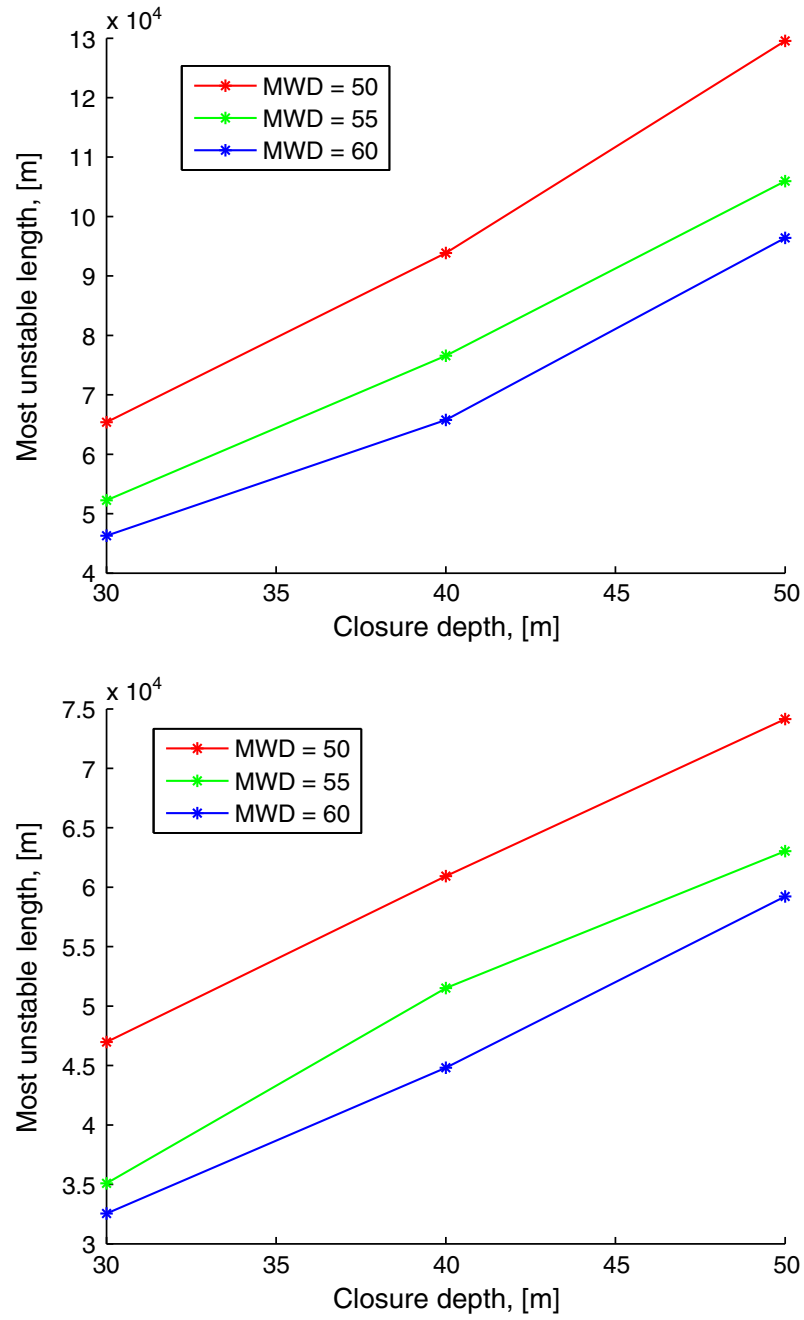

Fig. 15. Most unstable undulation length, $L$ as function of closure depth and mean wave direction for the case with a coastal profile steepness parameter $A_{b}=0.12$ (top) and $A_{b}=0.16$ (bottom).

both cases the selected coastal profile is only applied for water depths smaller than the depth of closure, beyond this depth, the water depth is kept constant and equal to the depth of closure.

Fig. 23 (left) shows the most unstable undulation length for different values of the mean wave direction and coastal profiles. When comparing the most unstable lengths presented in Fig. 23 (left) with the observed lengths on Srd. Holmslands Tange $(\approx 5-6 \mathrm{~km})$, it is observed that only if the closure depth is $5 \mathrm{~m}$, lengths of $\approx 5 \mathrm{~km}$ can be obtained in the model, i.e. with a closure depth of $7 \mathrm{~m}$ the smallest length of the most unstable undulation is $9 \mathrm{~km}$. Further, it is required that the mean wave angle at this depth forms an angle with the shoreline of $55^{\circ}$ or more.

It can be argued that the first requirement is satisfied at Srd. Holmslands Tange: in Kaergaard et al. (2012) it is found that the observed undulations are observed on the coastal face at the $5 \mathrm{~m}$ depth

Table 4

The combinations of coastal profile steepness, closure depth and mean wave direction which gives a fastest growing undulation length in the stability analysis, which resembles the observed length of $60 \mathrm{~km}$.

\begin{tabular}{lll}
\hline Parameter & Combi. 1 & Combi. 2 \\
\hline Beach profile steepness, $A_{b}$ & 0.16 & 0.16 \\
Closure depth, $D_{\text {cld }}$ & 40 & 50 \\
Mean wave direction, $M W D$ & $50^{\circ}$ & $55^{\circ}$ \\
Most unstable length, $L$ & $60 \mathrm{~km}$ & $60 \mathrm{~km}$ \\
\hline
\end{tabular}




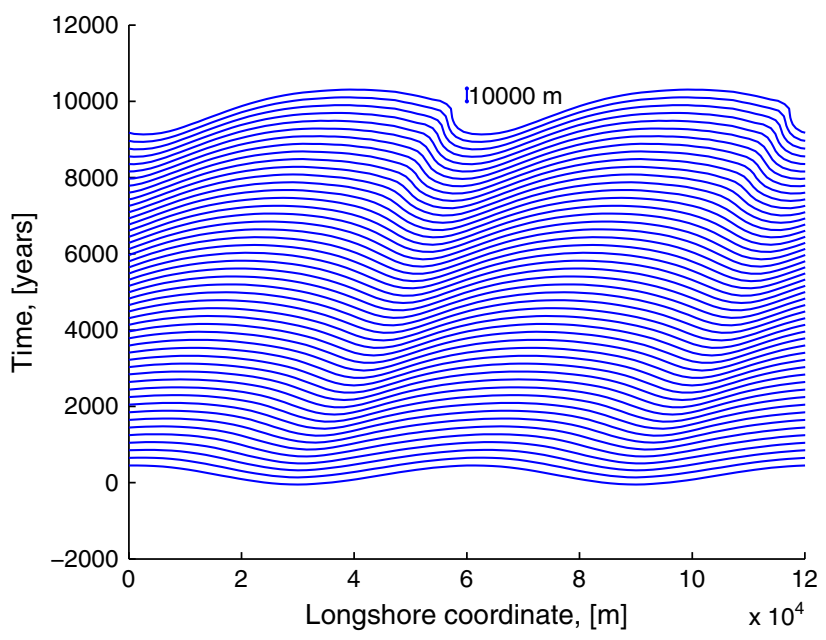

Fig. 16. Time stack of the shoreline evolution until the development of a spit on the downstream end of the undulation for the Combination 1 case in Table 4 .

contour, however, the data which are analyzed do not reach farther off-shore.

Regarding the wave angle, this can increase from $42^{\circ}$ on $25 \mathrm{~m}$ water depth, among other contributions, the north going "Jutland Current" with a speed around $1 \mathrm{~m} / \mathrm{s}$ will increase the wave angle, however no measurements are available to provide information on the exact increase.

\subsubsection{Discussion of wave input}

The results from the stability analysis of the shoreline show that the observed lengths of the shoreline undulations on this shoreline are only predicted by the stability analysis when the closure depth is not larger than $5 \mathrm{~m}$; i.e. just beyond the location where the average coastal profile changes its slope in each location. The angle of the incoming wave at this depth is usually quite small due to depth induced wave refraction; meaning that the waves are not in the unstable wave regime at this depth.

Fig. 24 shows the angle between the shoreline and the incoming waves as function of water depth for different wave periods. All waves start with an angle to the shoreline of $89^{\circ}$ in $30 \mathrm{~m}$ water depth, which is a reasonable average depth for the Danish part of the North Sea. At $5 \mathrm{~m}$ water depth, it is seen that only waves with period of $5 \mathrm{~s}$ or smaller, have angles larger than $50^{\circ}$. Thus, only short

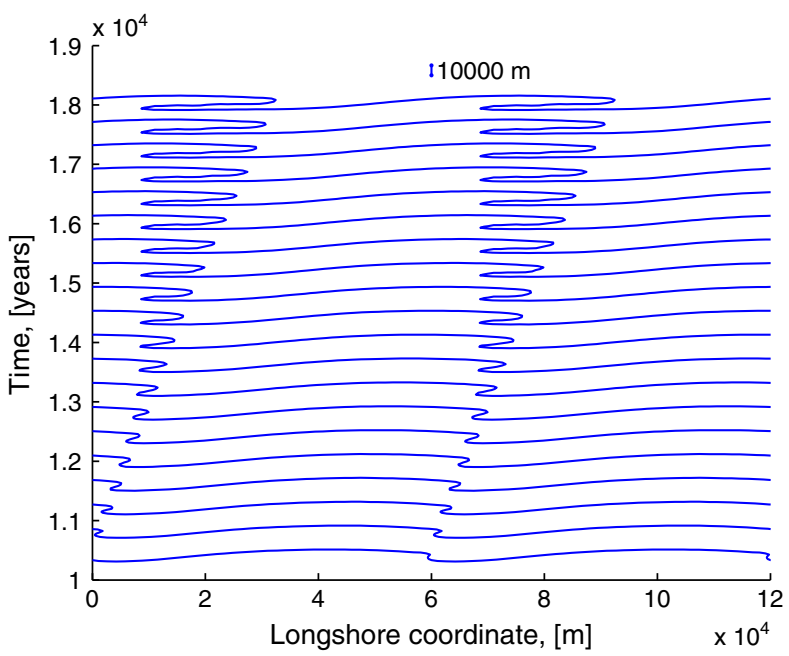

Fig. 17. Time stack of the shoreline evolution after the development of a spit on the downstream end of the undulation for the Combination 1 case in Table 4.

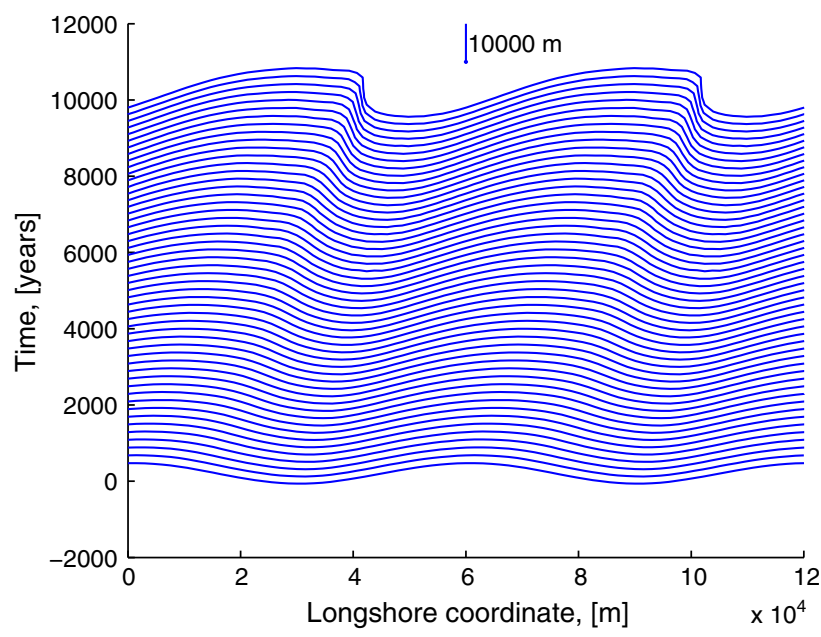

Fig. 18. Time stack of the shoreline evolution until the development of a spit on the downstream end of the undulation for the Combination 2 case in Table 4.

waves can reach a depth of around $5 \mathrm{~m}$ with a sufficiently large angle to be in the unstable regime.

The wave climate has been re-analyzed, this time only including waves with periods less than $5 \mathrm{~s}$ and $4 \mathrm{~s}$. The average mean wave direction for waves with periods smaller than $4 \mathrm{~s}$ was $\approx 58^{\circ}$, and average mean wave direction for waves with periods smaller than $5 \mathrm{~s}$ was $\approx 52^{\circ}$. For both cases only waves in the direction interval $100^{\circ}<\alpha<100^{\circ}$ ( $\alpha$ is the angle between the shoreline and the incoming waves), were used and no weighting of the wave directions was applied.

In Kaergaard et al. (2012), the average wave climate, i.e. without any weighing with the significant wave height, was applied to compare Srd. Holmslands Tange with the stability analysis by Falqués

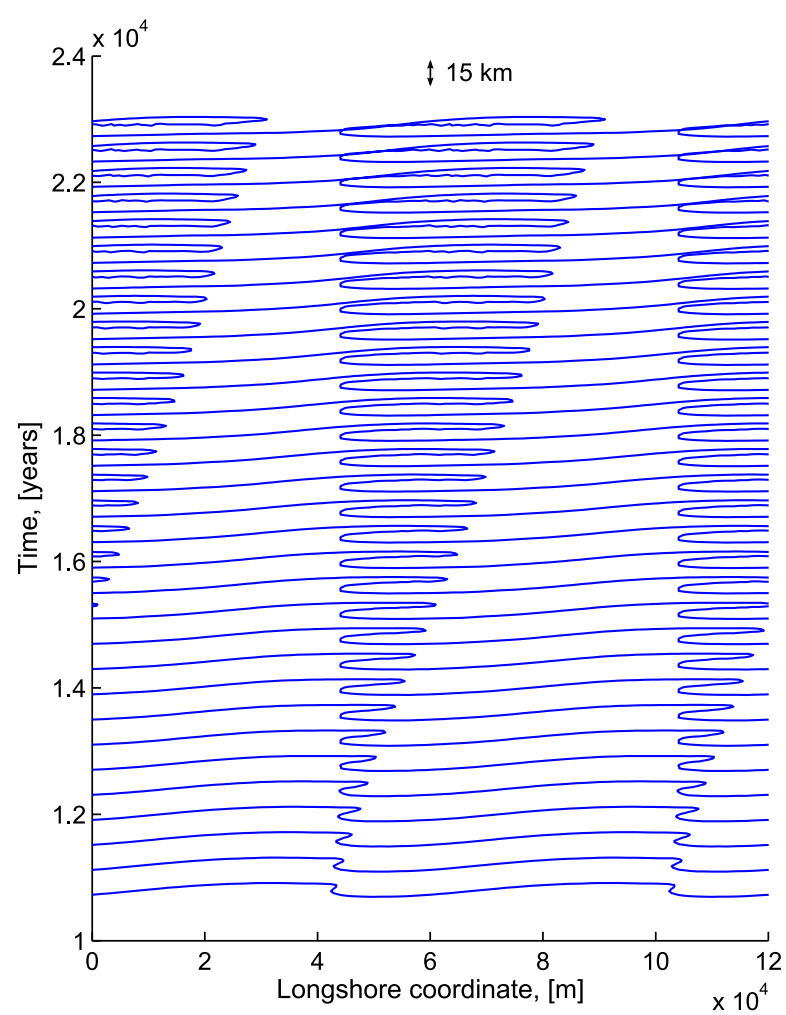

Fig. 19. Time stack of the shoreline evolution after the development of a spit on the downstream end of the undulation for the Combination 2 case in Table 4. 
Table 5

Undulation width, $w_{u}$, spit width, $w_{s}$, migration speed, $c$ and longshore sediment transport, $q$, at the end of the shoreline evolution simulations for the three combinations from Table 4.

\begin{tabular}{lllll}
\hline & $w_{u}$ & $w_{s}$ & $c$ & $q$ \\
\hline Combi. 1 & $13,500 \mathrm{~m}$ & $4500 \mathrm{~m}$ & $4.3 \mathrm{~m} /$ year & $1.7 \mathrm{M} \mathrm{m}^{3} /$ year \\
Combi. 2 & $15,000 \mathrm{~m}$ & $2400 \mathrm{~m}$ & $3.9 \mathrm{~m} /$ year & $1.6 \mathrm{M} \mathrm{m}^{3} /$ year \\
\hline
\end{tabular}

and Calvete (2005), and it was concluded that we were just on the limit between a stable and an unstable shoreline.

In the present work, the longshore undulations at Srd. Holmslands Tange can be explained by the shoreline instability, if the waves responsible for the undulations are the small "everyday" waves, and not the larger storm waves. The latter will refract so much, that they are in the stable wave regime before reaching the depth where shoreline undulations are imprinted on the bathymetry.

This raises the question: Why do the large storm waves not smoothen out the shoreline undulations? One possibility is that the outer longshore breaker bar dissipates most of the energy of the large storm waves before it reaches the shoreline, whereas the small waves responsible for the shoreline undulations pass the outer breaker bar unaffected.

\section{Discussion}

For the simulations with varying wave climates, three types of shoreline shapes develop in the model, depending on the varying wave climate: undulation with no spit, undulation with shore-parallel spit and undulation reconnecting spit. It is found that relatively small amounts of wave energy (20-30\%) from directions other than the main wave direction, prevents the formation of a spit.

The three types of shoreline shapes can be related to the shoreline shapes found by Ashton and Murray (2006a). The shore-parallel spits described in this paper do resemble their "flying spit", but there is a difference in the migration direction of the spit which is shore-parallel in the present work and off-shore directed in their work. The difference occurs because the curvature of the shoreline was ignored in their model, meaning that the migration direction of their spits is directed farther towards the off-shore compared to the results in the present work. Ashton and Murray (2006a)'s Fig. 9 shows, which types of shoreline shapes are obtained for different wave climates. Their fraction of

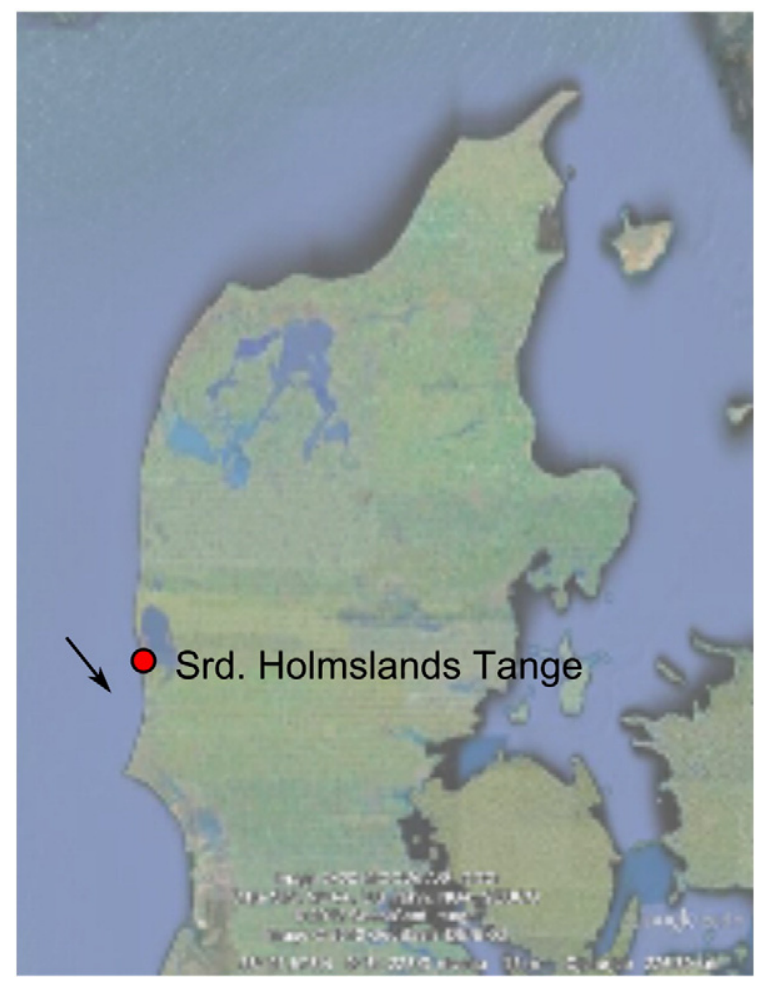

Fig. 21. Top: The location of Srd. Holmslands Tange on the west coast of Denmark. The main direction of the incoming waves is shown with the arrow.

waves from the unstable regime is $U=0.75$, whereas in the present work the lowest fraction is $U=0.8$, therefore these values are compared. In their model, spits are found for values of the $A$ down to $A \approx 0.57$ for $U=0.75$; $A$ being the fraction of waves from one side. In the present work $U=0.8$ gives no spits for any value of $A$, whereas for $U=0.9, A=0.8$ gives no spits, but $A=0.9$ gives reconnecting spits. The reason for this large discrepancy between the two models is probably due to the way spits grow in the two models. As shown by Petersen et al. (2008), in a shoreline model, where the curvature of the shoreline is ignored, the fastest growing spit is the infinitesimally narrow spit, which grows infinitely fast (the finite width of the spits in Ashton and Murray (2006a) is due to the changing wave climate).

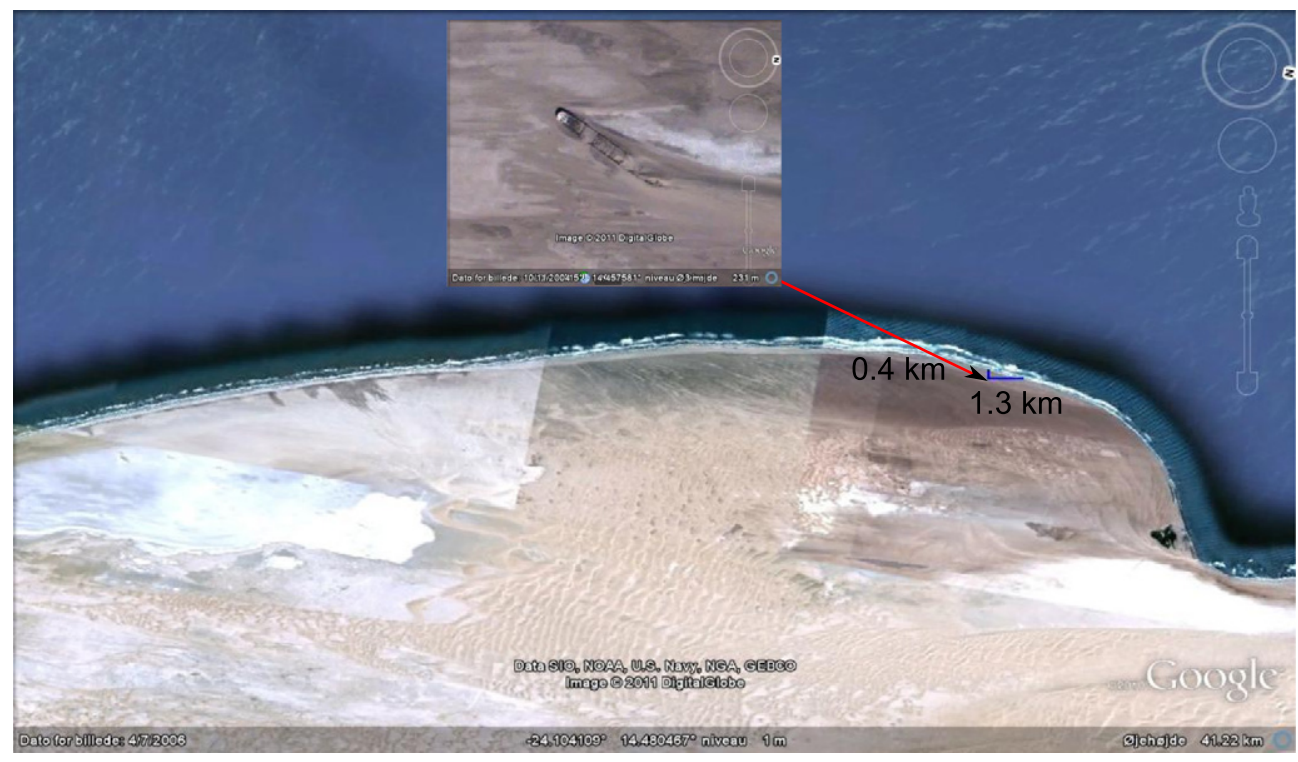

Fig. 20. Position of Eduard Bohlen on the southern most undulation on the west coast of Namibia. 


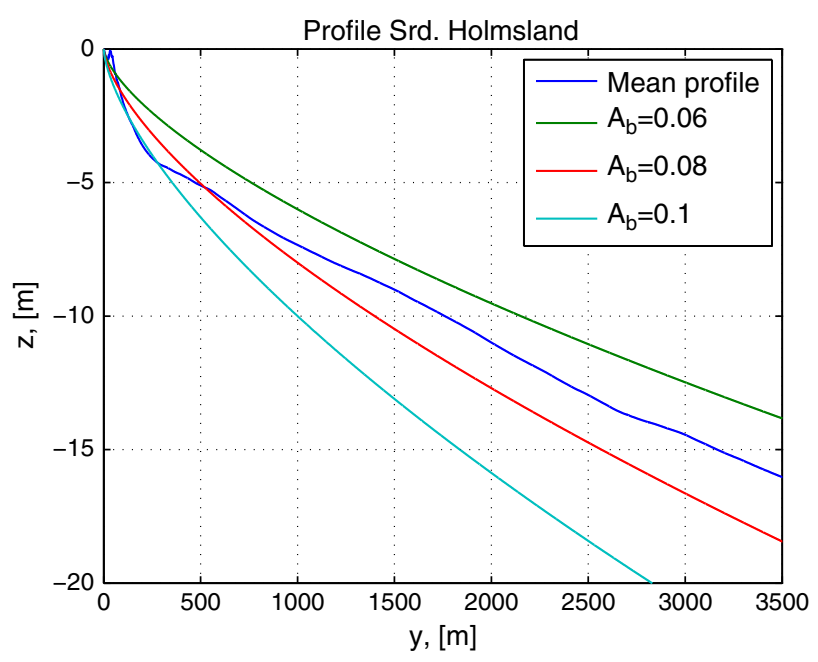

Fig. 22. The mean coastal profile at Srd. Holmslands Tange.

This is not the case in a model, which takes the curvature of the shoreline into account, here the width of the spit growing in the model is finite and likewise is the growth rate. Therefore the growth rate of the spits in the model by Ashton and Murray (2006a) is much larger than in the present model. Due to the higher growth rate, spits can form under wave climates that are more adverse to the formation of spits in their model compared to the present model.

The model has its limitations: the cross-shore profile is usually prescribed, and this shape is kept constant all along the shore. As also described in Kaergaard and Fredsoe (2013a), the right description of the cross-shore profile is essential for estimating the magnitude of the long shore sediment transport correctly. The model can most probably be improved by adding the effect of the cross-shore transport. The improvement will be largest where the radius of shoreline curvature is small as compared to the surf zone width.

Also, the interaction between undulations of different scales needs to be investigated further. Different scales can be observed in nature and certainly must have some impact on the evolution.

Finally, the choice how far away from the shore the undulation can be felt is a crucial parameter. Kaergaard et al. (2012) applied detailed measurements to conclude that the impact at least can be felt at a water depth more than 4 times the significant wave height, but this number must also depend on the wavelength of the undulation under investigation as well as on the peak wave period.

\section{Conclusion}

A numerical model capable of describing the evolution in time of the shoreline by a grid-adaptive net combined with a detailed multidirectional wave, long shore current and long shore sediment transport

Table 6

Model parameters used for the stability analysis at Srd. Holmsland Tange.

\begin{tabular}{lll}
\hline Parameter & Symbol & Value \\
\hline Wave parameters: & & \\
Significant wave height & $H_{s}$ & $1.8 \mathrm{~m}$ \\
Mean wave direction & $M W D$ & $50^{\circ}, 55^{\circ}$ \\
Directional Spreading Index & $D S I$ & 10 \\
Peak wave period & $T_{p}$ & $6.1 \mathrm{~s}$ \\
& & \\
Mesh: & $A_{b}$ & 0.1 and 0.08 \\
Dean profile steepness & $D_{\text {cld }}$ & 5 and $7 \mathrm{~m}$ \\
Closure depth & $a$ & $10 \mathrm{~m}$ \\
Cross-shore discretization & $n$ & 51 \\
Number of shoreline points & & \\
\hline
\end{tabular}

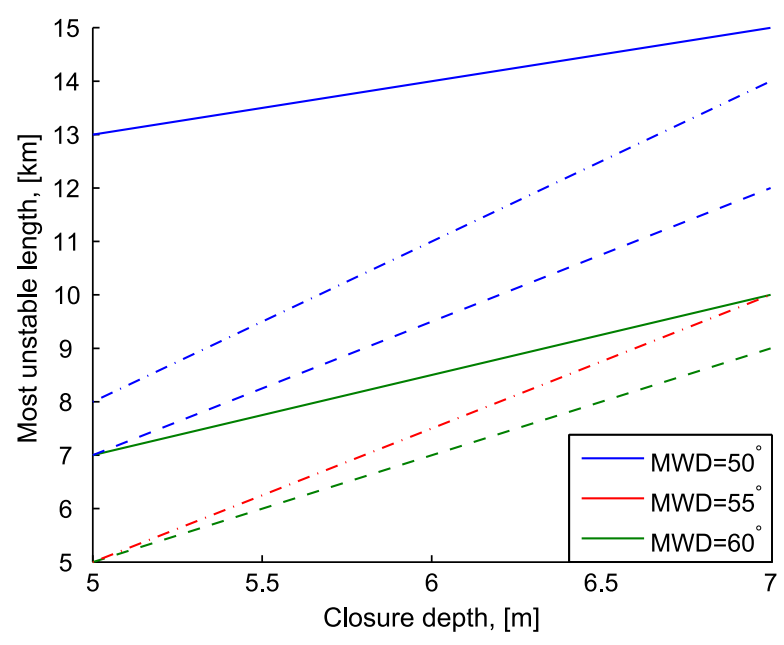

Fig. 23. The most unstable undulation length as function of closure depth, for different mean wave directions and coastal profiles for Srd. Holmslands Tange. The different coastal profiles are: Dean profile with $A_{b}=0.08$ (full lines), Dean profile with $A_{b}=$ 0.1 (dashed lines) and mean measured profile (dash-dotted lines).

description has been applied to compare the shoreline behavior of a coast exposed to very obliquely approaching waves with observed field data.

It is demonstrated that such a complete model can predict realistic shoreline features when introducing a realistic wave environment as forcing, i.e. waves with different angles of approach. The shoreline turns out into a main shape, which is asymmetric with a gentle up drift and a steeper down drift slope of the shore as compared to the original one.

Whether a spit is formed at the crest of the undulation depends on how strong the waves attack from the stable as well as unstable directions. This has been studied: if waves mainly attack from one direction as is the case in one of the cases studied, a spit aligned almost parallel to the original shore emerges in the model. This is in agreement with observed spits at many locations around the world. If the waves come from the right as well as the left and with comparable strength, no spit is formed, and you only get large scale undulations. This is also in accordance with observations.

Not all details can be captured by the model, because cross-shore sediment is not taken into account in modifying the cross-shore coastal profile to be steeper at some locations than others. Also the impact of closure depths is highlighted in the paper, this value is

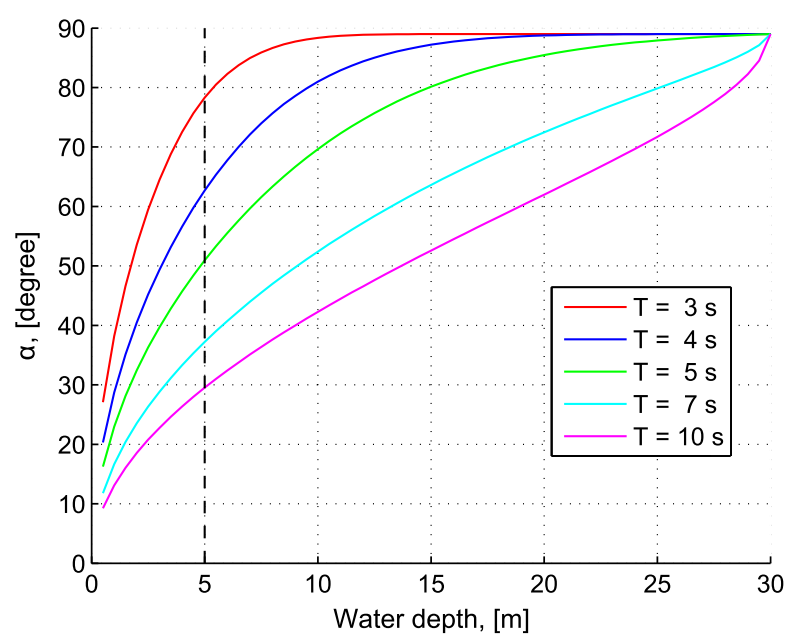

Fig. 24. The change in angle between incoming waves and shoreline, $\alpha$ due to depth induced wave refraction for different wave periods. 
crucial for the analysis. Both issues mentioned above suggest that further research on the topic needs to incorporate cross-shore sediment transport to improve the shoreline modeling further.

\section{Acknowledgments}

The work presented in the present paper was equally financed by DHI Water \& Environment and the Danish Technical University; both institutions are thanked for their cooperation.

\section{References}

Ashton, A., Murray, A., 2006a. High-angle wave instability and emergent shoreline shapes: 2. Wave climate analysis and comparisons to nature. Journal of Geophysical ResearchEarth Surface 111 (F4).

Ashton, A.D., Murray, A.B., 2006b. High-angle wave instability and emergent shoreline shapes: 1 . Modeling of sand waves, flying spits, and capes. Journal of Geophysical Research 111 (F4)

Bosman, D., Joubert, J.R., 2008. Walvis Bay Port Extension Report on Wave, Wind and Water Level Conditions at Walvis Bay. Tech. rep. Dept Civil Engineering, University of Stellenbosch, Namibia.

Dean, R., 1991. Equilibrium beach profiles - characteristics and applications. Journal of Coastal Research 7 (1), 53-84.

Elfrink, B., Prestedge, G., Rocha, C., Juhl, J., 2003. Shoreline evolution due to highly oblique incident waves at Walvis Bay, Namibia. Proceedings of the International Conference on Coastal Sediments 2003. World Sci.

Falqués, A., Calvete, D., 2005. Large-scale dynamics of sandy coastlines: diffusivity and instability. Journal of Geophysical Research 110 C03007. http://dx.doi.org/10. 1029/2004JC002587.

Fourriere, A., Claudin, P., Andreotti, B., 2010. Bedforms in a turbulent stream: formation of ripples by primary linear instability and of dunes by nonlinear pattern coarsening. Journal of Fluid Mechanics 649, 287.
Hallermeier, R., 1981. A profile zonation for seasonal sand beaches from wave climate Coastal Engineering 4 (3), 253-277.

Hanson, H., 1989. GENESIS - a generalized shoreline change numerical-model. Journal of Coastal Research 5 (1), 1-27.

Hughes, P., Brundrit, G., Searson, S., 1992. The vulnerability of Walvis Bay to rising sea levels. Journal of Coastal Research 8 (4), 868-881.

Inman, D.L., Elwany, M.H.S., Jenkins, S.A., 1993. Shore rise and Bar-Berm profiles on ocean beaches. Journal of Geophysical Research 98 (C10), 18,181-18,199.

Kaergaard, K., Fredsoe, J., 2013a. Numerical shoreline model for shorelines with large curvature. Coastal Engineering (In print).

Kaergaard, K., Fredsoe, J., 2013b. Numerical simulation of longshore shoreline undulations, part 1: constant wave climate. Coastal Engineering (In print).

Kaergaard, K., Fredsoe, J., Knudsen, S., 2012. Coastline undulations on the west coast of Denmark: off-shore extent, relation to breaker bars and transported sediment volume. Coastal Engineering 60, 109-122. http://dx.doi.org/10.1016/j.coastaleng.2011.09.002.

Komar, P., Inman, D., 1970. Longshore sand transport on beaches. Journal of Geophysical Research 75 (30), 5914-5927.

Kystdirektoratet, 1999. Sedimentanalyse vestkysten. Tech. Rep., Kystdirektoratet.

Leroux, P., 1974. Drift sand reclamation of Walvis-Bay, south-west-Africa. International Journal of Biometeorology 18 (2), 121-127.

Petersen, K.S., 1991. Holocene coastal and faunal development of the Skagen Odde, northern Jutland, Denmark. Quaternary International 9, 53-60.

Petersen, D., Deigaard, R., Fredsoe, J., 2008. Modelling the morphology of sandy spits. Coastal Engineering 55 (7-8), 671-684.

Schoonees, J., Lenhoff, L., Raw, A., 1998. Preventing natural breaching of the major sand spit protecting the port of Walvis Bay. Proceedings of the 26th Coastal Engineering Conference Vol. 3, pp. 1475-1488.

Uguccioni, L., Deigaard, R., Fredsoe, J., 2006. Instability of a coastline with very oblique wave incidence. Proceedings of the 30th Coastal Engineering Conference, Vol. 1-5, pp. 3542-3553.

van den Berg, N., Falqués, A., Ribas, F., 2012. Modeling large scale shoreline sand waves under oblique wave incidence. Journal of Geophysical Research 117 F03019. http://dx.doi.org/10.1029/2011JF002177. 